\title{
Exergy destruction and losses on four North Sea offshore platforms: A comparative study of the oil and gas processing plants
}

Voldsund, Mari ; Nguyen, Tuong-Van; Elmegaard, Brian; Ertesvåg, Ivan S.; Røsjorde, Audun; Jøssang, Knut; Kjelstrup, Signe

\section{Published in:}

Energy

Link to article, DOI:

10.1016/j.energy.2014.02.080

Publication date:

2014

Document Version

Peer reviewed version

Link back to DTU Orbit

Citation (APA):

Voldsund, M., Nguyen, T-V., Elmegaard, B., Ertesvåg, I. S., Røsjorde, A., Jøssang, K., \& Kjelstrup, S. (2014). Exergy destruction and losses on four North Sea offshore platforms: A comparative study of the oil and gas processing plants. Energy, 74, 45-58. https://doi.org/10.1016/j.energy.2014.02.080

\section{General rights}

Copyright and moral rights for the publications made accessible in the public portal are retained by the authors and/or other copyright owners and it is a condition of accessing publications that users recognise and abide by the legal requirements associated with these rights.

- Users may download and print one copy of any publication from the public portal for the purpose of private study or research.

- You may not further distribute the material or use it for any profit-making activity or commercial gain

- You may freely distribute the URL identifying the publication in the public portal 


\title{
Exergy destruction and losses on four North Sea offshore platforms: A comparative study of the oil and gas processing plants
}

\author{
Mari Voldsund ${ }^{\mathrm{a}}$, Tuong-Van Nguyen ${ }^{\mathrm{b}}$, Brian Elmegaard ${ }^{\mathrm{b}}$, Ivar Ståle Ertesvåg ${ }^{\mathrm{c}}$, Audun Røsjorde ${ }^{\mathrm{d}}$, Knut \\ Jøssang ${ }^{c}$, Signe Kjelstrup ${ }^{\mathrm{a}}$ \\ ${ }^{a}$ Department of Chemistry, Norwegian University of Science and Technology, \\ Høgskoleringen 5, NO-7491 Trondheim, Norway \\ ${ }^{b}$ Section of Thermal Energy, Department of Mechanical Engineering, Technical University of Denmark, \\ Building 403, Nils Koppels Allé, DK-2800 Kongens Lyngby, Denmark \\ ${ }^{c}$ Department of Energy and Process Engineering, Norwegian University of Science and Technology \\ Kolbjørn Hejes vei 1b, NO-7491 Trondheim, Norway \\ ${ }^{d}$ Statoil ASA \\ Martin Linges vei 33, NO-1364 Fornebu, Norway
}

\begin{abstract}
The oil and gas processing plants of four North Sea offshore platforms are analysed and compared, based on the exergy analysis method. Sources of exergy destruction and losses are identified and the findings for the different platforms are compared. Different platforms have different working conditions, which implies that some platforms need less heat and power than others. Reservoir properties and composition vary over the lifetime of an oil field, and therefore maintaining a high efficiency of the processing plant is challenging. The results of the analysis show that $27 \%-57 \%$ of the exergy destruction take place in the gas treatment sections, $13 \%-29 \%$ take place in the gas recompression sections and $10 \%-24 \%$ occur in the production manifolds. The exergy losses with flared gas are significant for two of the platforms. The exact potential for energy savings and for enhancing system performances differs across offshore platforms. However, the results indicate that the largest rooms for improvement lie in (i) gas compression systems where large amounts of gas may be compressed and recycled to prevent surge, (ii) production manifolds where well-streams are depressurised and mixed, and (iii) in the installation of flare gas recovery systems.
\end{abstract}

Keywords: Exergy, Oil and gas, Energy, Efficiency

\section{Introduction}

Oil and gas processing on North Sea offshore platforms consumes substantial amounts of power and has a significant environmental impact, being responsible for about $26 \%$ of the total greenhouse gas emissions of Norway in 2011 [1]. Onsite processes on offshore facilities suffer from significant performance losses over the lifetime of the installation, as a consequence of substantial variations of the reservoir properties (e.g. pressure and temperature) and of the production flow rates and composition (e.g. gas-to-oil and water-to-oil ratios, crude oil properties). These off-design conditions lead to the use of control strategies such as antisurge recycling [2], and thus to greater power consumption and larger exergy destruction. Moreover, as the oil production decreases with time, energy-intensive techniques such as gas and water injection are employed to enhance oil recovery from the reservoir. It is therefore challenging to maintain a high performance of the overall system over time, while optimising the oil and gas production.

Email addresses: mari.voldsund@ntnu.no (Mari Voldsund), tungu@mek.dtu.dk (Tuong-Van Nguyen), be@mek.dtu.dk (Brian Elmegaard), ivar.s.ertesvag@ntnu.no (Ivar Ståle Ertesvåg), audr@statoil.com (Audun Røsjorde), knutjos@stud.ntnu.no (Knut Jøssang), signe.kjelstrup@ntnu .no (Signe Kjelstrup) 


\begin{tabular}{|c|c|c|c|}
\hline \multicolumn{4}{|c|}{ Nomenclature } \\
\hline$T$ & Temperature, $\mathrm{K}$ & kin & kinetic \\
\hline$\dot{E}$ & Exergy rate, $\mathrm{W}$ & $\operatorname{mix}$ & mixture \\
\hline$\dot{m}$ & mass flow rate, $\mathrm{kg} / \mathrm{s}$ & $\mathrm{ph}$ & physical \\
\hline$e$ & specific exergy, $\mathrm{J} / \mathrm{kg}$ & pot & potential \\
\hline$h$ & specific enthalpy, $\mathrm{J} / \mathrm{kg}$ & $\mathrm{Q}$ & heat \\
\hline$p$ & pressure, $\mathrm{Pa}$ & W & work \\
\hline$s$ & specific entropy, J/kgK & \multicolumn{2}{|c|}{ Subscripts } \\
\hline$x$ & mass fraction & $i$ & component \\
\hline $\mathrm{W}$ & $\begin{array}{l}\text { thermal energy } \\
\text { work }\end{array}$ & 0 & dead state \\
\hline Abbr & ations & $\mathrm{d}$ & destruction \\
\hline EOS & Equation of state & in & inlet \\
\hline Super & ripts & 1 & loss \\
\hline $\mathrm{ch}$ & chemical & out & outlet \\
\hline
\end{tabular}

Svalheim and King [3] stressed the large power demand of the gas compression and water injection processes over the lifespan of the oilfield. To the knowledge of the authors, it is the only study in the open literature that investigates the life of field variations of the energy demand of oil and gas facilities. The variations are due to changes in field pressure, water-to-oil and gas-to-oil ratios over the lifetime of the field. Their studies also emphasised the benefits that resulted from applying best practices in energy management (e.g. gas turbine operation near design load, reduction of flaring and venting practices, and integration of waste heat recovery). Similarly, Kloster [4,5] argued that these measures could and did contribute to significant energy savings and a reduction of the $\mathrm{CO}_{2}$-emissions of the Norwegian oil and gas installations. A mapping of the thermodynamic inefficiencies is useful, as it indicates room for improvements in a rational manner. Such information can be obtained by carrying out an exergetic analysis, which is based on both the 1st and 2nd laws of thermodynamics. The exergy of a system is defined as the maximum theoretical ability to do work when it interacts with the environment, and is, unlike energy, not conserved in real processes [6]. An exergy accounting reveals the locations and extents of thermodynamic irreversibilities present in a given system, and these irreversibilities account for a greater fuel use throughout successive processes [7].

Oliveira and Van Hombeeck [8] conducted an exergy analysis of a Brazilian oil platform which included the separation, compression and pumping modules but not the production manifolds. Their work showed that the least exergy-efficient subsystem was the oil and gas separation, while the most exergy-consuming ones were the petroleum heating and the gas compression processes. Voldsund et al. [9] carried out an exergy analysis of a Norwegian oil platform and considered the production manifold, the separation and recompression processes, the fuel gas subsystem and the oil pumping and gas reinjection trains. Their study demonstrated that the largest exergy destruction took place in the production manifold and in the gas reinjection systems. There were no considerable petroleum heating operations on this platform, since the feed temperature was high enough for separation of the specific oil by pressure reduction only, and thus there was no exergy destruction due to heating operations. Nguyen et al. [10] conducted a generic analysis of Norwegian oil and gas facilities. Their work suggested that the production manifold and gas compression trains were generally the most exergy-destructive parts, followed by the recompression and separation modules. It was also shown that these results were particularly sensitive to the compressor and pump efficiencies, as well as to the petroleum composition. 
The similitude and discrepancies in the results of these studies suggest that differences in the design setup and in the field conditions may affect the locations and extents of the thermodynamic irreversibilities of the overall system. The literature appears to contain no systematic comparison of the sources of exergy destruction for oil and gas platforms. Therefore, in this work, the platform analysed by Voldsund et al. [9] is compared with three other North Sea offshore platforms, which have not been studied in this manner before. The variations of the reservoir fluid composition over the life cycle of each field are not investigated, but it is worth emphasising that the four platforms operate at a different production period of an oilfield (peak and end-life). The work was carried out in three main steps:

- simulation and investigation of the platforms;

- exergy accounting;

- comparison of the four platforms, based on the outcomes from the two previous steps.

The present paper is part of two projects dealing with modelling and analysis of oil and gas producing platforms. It builds on previous works conducted by the same authors and is structured as follows: Section 2 describes the followed methodology, with a strong emphasis on the system description and on the similarities and differences between the four cases. Section 3 presents a comparison of the results obtained for each platform. The results are discussed in Section 4 and are followed by concluding remarks in Section 5 .

\section{Methodology}

\subsection{System description}

The purpose of an offshore platform is to extract, process and export petroleum. A typical offshore platform consists of a processing section, utilities, drilling modules, and a living quarter. The focus of this study is the processing of oil and gas, which takes place in the processing section. All power and heat that are needed in the processing section are delivered by power turbines and heat recovery systems that are part of the utilities, normally by combustion of the natural gas produced at the platform. A flare gas system, which is also a part of the utilities, handles gas released during unplanned over-pressuring of plant equipment and small volumes of waste gas that cannot be easily captured and returned to the system for processing.

The structural designs of the processing plants on the four platforms are similar. Meanwhile, different reservoir fluid characteristics and reservoir properties, as well as different requirements for the products, have resulted in dissimilar temperatures, pressures and flow rates throughout the process, and different demands for compression, heating, cooling and treatment.

In Section 2.1.1 we give a generalised overview of the oil and gas processing plant for the studied platforms, in Section 2.1.2 we present key information on the platforms, to indicate the main differences between them, and in Section 2.1.3 we list process data that are important to explain the different results for the platforms.

\subsubsection{A generalised overview of the processing plant}

An overview of the processing plants on the four platforms, with subsystems and material streams, is shown schematically in Fig. 1. This figure shows the common overall set-up of the processing plants. The detailed process set-ups are illustrated in Figs. A.7-A.10. Well fluids from several producing wells (1) enter one or more production manifolds where pressure is reduced and streams from the different wells are mixed. The mixed streams (2) are sent to a separation train where oil, gas and water are separated in several stages by reducing pressure in each step, and where heating may be required.

Oil or condensate (3) is sent to the main oil/condensate treatment section where it is pumped for further export (4). Produced gas is compressed in a recompression train to match the pressure of the stream entering the separation train (2). This compression is done in several stages, each stage with a cooler, a scrubber and a compressor. Condensate from the recompression train is sent back to the separation train, while compressed gas is sent to the gas treatment section. 
The produced gas is treated differently on the four platforms, with different demands for compression and dehydration, depending on the properties of the gas and on whether the product (5) is to be exported or used for enhanced oil recovery. This can be performed either with gas injection, where gas is injected into the reservoir in order to maintain a high pressure, or gas lift, where gas is injected in the wells in order to reduce the density of the well-streams. On one of the platforms additional gas is imported (9) and compressed in this section. Condensate from the gas treatment is either recycled to the separation train or pumped, dehydrated and exported (6) in a separate condensate treatment section. Fuel gas is taken from one of the streams with produced gas, treated in a fuel gas system and sent (8) to the power turbines, and for two of the platforms also to the flares for pilot flames.

From each of the subsystems shown in Fig. 1, except from the seawater injection system, some gas may be sent to the flares, in urgency cases and/or in order to maintain a stable production. The amount of flared gas is normally negligible compared to the main hydrocarbon flows, representing less than $2 \%$ of the total exergy of the crude oil and gas flows. In special cases large amounts of gas may be flared to avoid emergencies.

Produced water (7) is treated and either discharged to the sea or injected into another reservoir. Seawater (10) may be compressed for injection into the producing reservoir for enhanced recovery (11).

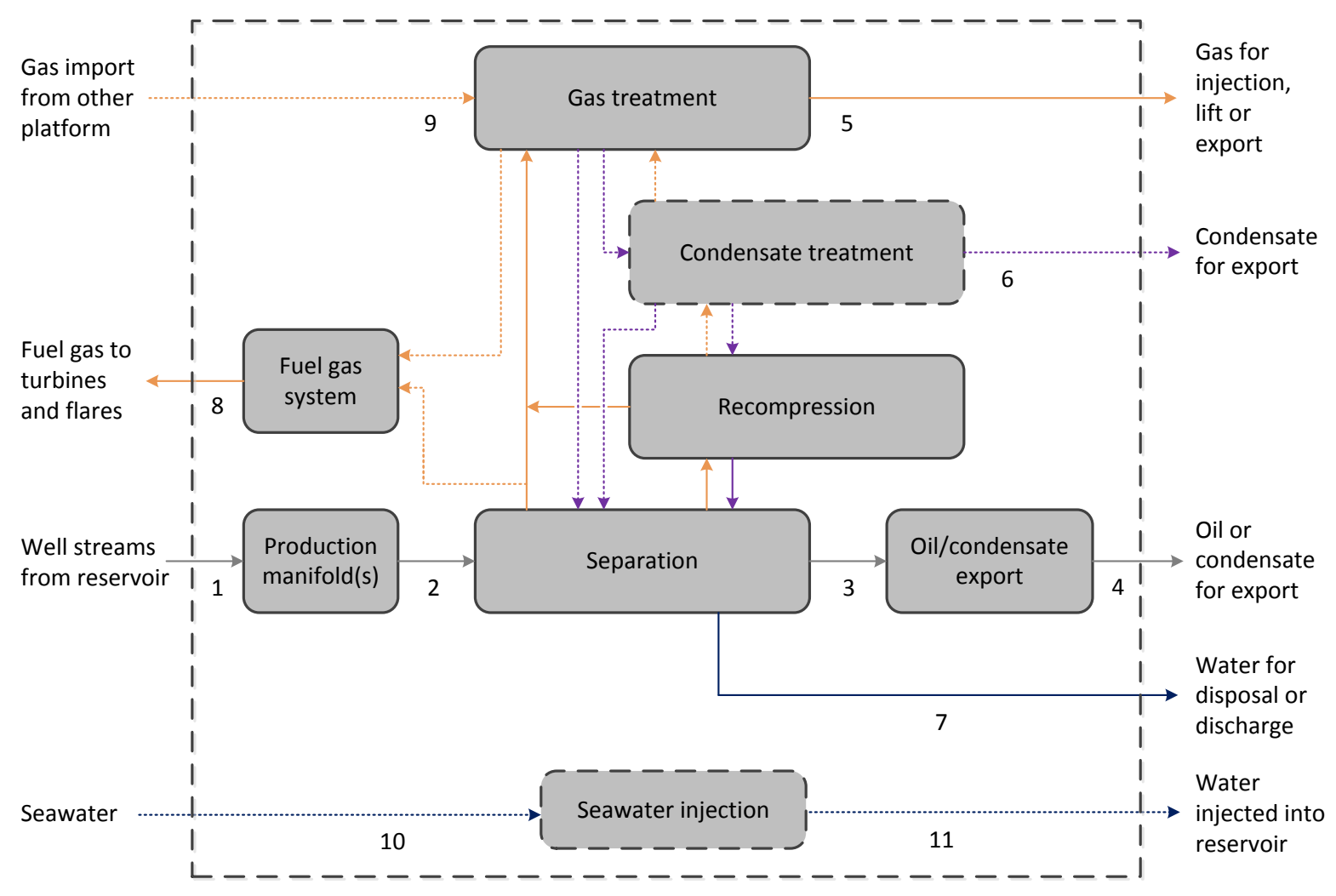

Figure 1: A generalised overview of the processing plant on the four North Sea platforms. The arrows represent one or several mass streams while the blocks represent subsystems. Dotted arrows and blocks are not present at all four platforms. Flared and vented gases come from several sections of the processing plant and are not shown in the figure for readability.

\subsubsection{Key information on the studied platforms}

The studied platforms are labelled Platform A, B, C and D, and their main characteristics are given below: 
- Platform A has been in production for approximately 20 years and is characterised by a high gasto-oil ratio. Oil is pumped to a nearby platform while gas is injected into the reservoir for pressure maintenance. Water injection is also used as a recovery technique, but the injection water is produced at another platform, and is therefore not taken into consideration in this analysis. Produced water is discharged to the sea. Platform A was investigated in previous works of the same authors and more details of the analysis can be found in [9].

- Platform B has been in production for approximately 10 years. It has high reservoir temperature, pressure and gas-to-oil ratio and produces gas and condensate through pressure depletion. The exported gas is not dehydrated. Produced water is injected into another reservoir for disposal. Power consumption is small because of a relatively low compression demand. There is some heat integration between process streams with cooling- and heating demand.

- Platform $\mathrm{C}$ has also been in production for approximately 10 years. It produces oil with high viscosity, and heating is required to ease the crude oil-water separation. The heating demand is met by waste heat recovery from the exhaust gases exiting the gas turbines, and by heat integration with other process streams. Gas lift and gas injection are used as recovery strategies: however, the gas-to-oil ratio of this field is small and gas is therefore imported. Produced water is discharged to the sea. A flare gas recovery system is installed. An exergetic assessment of this platform was also presented by Jøssang [11].

- Platform D has been in production for approximately 20 years, and gas, oil and condensate are exported. The treatment of condensate is due to a high propane content in the reservoir fluid and is done to prevent recirculation of medium-weight alkanes in the separation and recompression trains. Both gas and condensate are dehydrated. Condensate and gas are mixed at the outlet of the condensate treatment section and are exported in the same pipeline network. Heating is required to enhance separation of oil, gas and water, for regenerating the glycol used for dehydration, and for fractionating condensate. Gas lift and water injection are used to enhance oil recovery.

The gas-to-oil ratios and product flow rates for each of the studied platforms are given in Table 1. Volume flows are estimated at a temperature of $15{ }^{\circ} \mathrm{C}$ and a pressure of 1.013 bar. These conditions are denoted standard and are used as a norm by e.g. the Norwegian Petroleum Directorate. It should be noted that the choice of these conditions only impacts the values of the volume flows, and is not related to the choice of the reference conditions for the energy and exergy analyses.

Table 1: Gas-to-oil ratios and product flow rates for the studied oil and gas platforms. Gas-to-oil ratio is given on a standard volume basis.

\begin{tabular}{lrrrr}
\hline & Platform A & Platform B & Platform C & Platform D \\
\hline Gas-to-oil ratio [-] & 2800 & 3200 & 360 & 230 \\
Exported oil/condensate $\left[\mathrm{Sm}^{3} / \mathrm{h}\right]$ & 133 & 239 & 1105 & 271 \\
Exported gas $\left[10^{3} \mathrm{Sm}^{3} / \mathrm{h}\right]$ & - & 761 & - & 7.9 \\
Injected gas $\left[10^{3} \mathrm{Sm}^{3} / \mathrm{h}\right]$ & 369 & - & 363 & - \\
Lift gas $\left[10^{3} \mathrm{Sm}^{3} / \mathrm{h}\right]$ & - & - & 22 & 49.4 \\
Produced water $\left[\mathrm{Sm}^{3} / \mathrm{h}\right]$ & 67 & 12 & 250 & 1110 \\
Injected seawater $\left[\mathrm{Sm}^{3} / \mathrm{h}\right]$ & - & - & - & 890 \\
\hline
\end{tabular}

\subsubsection{Process details}

Temperatures and pressures for key streams are given in Table 2. The values given as range (e.g. 64111 for Platform B, Table 2) mean that the reservoir fluids are extracted through different wells, which are located at different depths and are thus operated at different temperatures. The following points are essential for a better understanding of the outcome of the analysis: 
- Pressure is reduced in the production manifold and the separation train. Well stream pressures, $p_{1}$, and pressures into the separation train, $p_{2}$, vary between the platforms, while pressure out of the separation train, $p_{3}$, ranges between 1.7 and 2.8 bar for all platforms, due to vapor pressure requirements for the oil/condensate export.

- Temperatures at the outlet of the production manifold, $T_{2}$, are higher for Platforms $\mathrm{A}$ and $\mathrm{B}$ than for Platforms C and D. No heating is required in order to separate the well streams of the first two platforms, while the low temperature together with the petroleum characteristics make heating necessary for the latter two. Export pipelines are subject to practical constraints such as limitations on the operating temperatures, and low temperatures at the inlets of the pumps and compressors are preferred for efficient operation. Thus, the well stream temperatures have effect on the heating demands, and also to a certain extent on the cooling demands of the platforms.

- In the export pumping section the pressure of the produced oil or condensate is increased from $p_{3}$ to $p_{4}$. The magnitude of $p_{4}$ depends on the export requirements.

- The gas treatment section differs across the platforms, depending on the conditions of the incoming gas, and the planned use of it. On Platforms A, C and D the pressure is increased from $p_{2}$ to $p_{5}$, since the produced gas is to be injected, used for gas lifting or exported at a pressure higher than $p_{2}$. On Platform B the gas is not compressed. Since the well-stream pressure is high, the operators can allow a pressure at the outlet of the production manifold higher than the pressure required for export, so $p_{5}$ is lower than $p_{2}$. For a detailed overview of the structural design of this section in each of the platforms, we refer to Figs. A.7-A.10.

- The imported gas on Platform $\mathrm{C}$ is compressed from $p_{9}$ to $p_{5}$ in the gas treatment section.

- On Platform D seawater is pressurised from $p_{10}$ (ambient) to $p_{11}$ and injected.

Table 2: Pressures and temperatures in the oil- and gas processing of the studied oil and gas platforms.

\begin{tabular}{|c|c|c|c|c|c|c|c|c|}
\hline \multirow{2}{*}{$\begin{array}{l}\text { Stream number } \\
\text { (type) }\end{array}$} & \multicolumn{2}{|c|}{ Platform A } & \multicolumn{2}{|c|}{ Platform B } & \multicolumn{2}{|c|}{ Platform C } & \multicolumn{2}{|c|}{ Platform D } \\
\hline & $p[\mathrm{bar}]$ & $T\left[{ }^{\circ} \mathrm{C}\right]$ & $p$ [bar] & $T\left[{ }^{\circ} \mathrm{C}\right]$ & $p$ [bar] & $T\left[{ }^{\circ} \mathrm{C}\right]$ & $p$ [bar] & $T\left[{ }^{\circ} \mathrm{C}\right]$ \\
\hline \multirow[t]{2}{*}{1 (reservoir fluids) } & $88-165$ & $80-87$ & $123-155$ & $64-111$ & $13-111$ & $51-72$ & $15-187$ & $55-74$ \\
\hline & & & & & $46^{a}$ & $62^{a}$ & & $49-67$ \\
\hline \multirow[t]{2}{*}{2 (reservoir fluids) } & 70 & 74 & 120 & 106 & $7^{b}$ & $69^{b}$ & 8 & $63^{b}$ \\
\hline & & & & & $13^{c}$ & $65^{c}$ & & \\
\hline 3 (oil/condensate) & 2.8 & 55 & 2.4 & 62 & 2.7 & 97 & 1.7 & $45-55$ \\
\hline 4 (oil/condensate) & 32 & 50 & 107 & 56 & 99 & 76 & 19 & $61-68$ \\
\hline 5 (treated gas) & 236 & 78 & 118 & 35 & 184 & 75 & 179 & 81 \\
\hline 6 (condensate) & - & & - & - & - & - & 179 & 68 \\
\hline 7 (produced water) & 9 & 73 & 61 & 78 & 7.2 & 72 & 1.3 & 55 \\
\hline 8 (fuel gas) & 18 & 54 & 37 & 50 & 39 & 61 & 21 & 59 \\
\hline 9 (gas import) & - & - & - & - & 110 & 4.4 & - & - \\
\hline 10 (inlet seawater) & - & - & - & - & - & - & 1 & 8 \\
\hline 11 (injection seawater) & - & - & - & - & - & - & $127-147$ & 57 \\
\hline
\end{tabular}

${ }^{a}$ From high pressure manifold

${ }^{b}$ From low pressure manifold

${ }^{c}$ From test manifold

Since flow rates throughout the process change over the field lifetime, some parts are run at lower flow rates than the process equipment was designed for. To avoid compressor surging in this situation, gas is recycled around the compression stages, to keep a minimum flow rate through the compressor. The recycled gas is also sent through the cooler and the scrubber of the compression stage (see Figs.A.7-A.10 for the exact process set-up), to keep a low temperature and remove the liquid resulting from the cooling. Gas recycling only takes place within a given sub-system (e.g. recompression or compression). The gas recycling 
rates around compressor stages in the various compression sections of the four platforms are given in Table 3. There is anti-surge recycling in the recompression trains of all platforms, while in the gas treatment section there is recycling of the imported gas in Platform B and of the produced gas in Platform D.

Table 3: Anti-surge recycle rates in the various compression sections of the studied oil and gas platforms, given as percentage of the flow through the compressors.

\begin{tabular}{lrrrrr}
\hline & & Platform A & Platform B & Platform C & Platform D \\
\hline Recompression train & {$[\%]$} & $69-92$ & $4-34$ & $32-44$ & $65-75$ \\
Gas treatment, produced gas compression & {$[\%]$} & 0 & - & 0 & $5-35$ \\
Gas treatment, import gas compression & {$[\%]$} & - & - & 22 & - \\
\hline
\end{tabular}

\subsection{Process simulation}

One typical production day was simulated for each platform. The simulations were built on measured values and on values assumed or found in documentation of equipment. The measured values used for Platforms A, B and D are mean values for the simulated day, while the values for Platform C are measured at 12:00. The simulated production days were days with stable conditions, meaning that the standard deviations for the flow rates throughout the day for exported oil or condensate were either lower than 10 $\mathrm{Sm}^{3} / \mathrm{h}$ or $3 \%$ and the standard deviation of produced gas was lower than $2 \%$ (Table 4 ). The basic data used in the simulations is available in the literature [9] for Platform A, in the supplementary information of this paper for Platforms B and C, and it is confidential for Platform D.

Table 4: Standard deviation in measured flow rates of produced oil, condensate and gas for Platforms A, B and D for the simulated days. The values given for Platform $\mathrm{C}$ (marked with ${ }^{*}$ ) are maximum deviation through the day from the value measured at 12:00

\begin{tabular}{lrrrrr} 
& & Platform A & Platform B & Platform C & Platform D \\
\hline Exported oil & {$\left[\mathrm{Sm}^{3} / \mathrm{h}\right]$} & 9 & 7 & $8^{*}$ & 2.2 \\
& {$[\%]$} & 7 & 3 & $0.7^{*}$ & 0.80 \\
Lift-, injected or exported gas & {$\left[\mathrm{Sm}^{3} / \mathrm{h}\right]$} & $\leq 0.8 \cdot 10^{3}$ & $8 \cdot 10^{3}$ & $6 \cdot 10^{3 *}$ & $55 \cdot 10^{3}$ \\
& {$[\%]$} & $\leq 0.2$ & 1.1 & $1.7^{*}$ & 0.7 \\
\hline
\end{tabular}

Platforms A, C and D process oil and gas, and the Peng-Robinson equation of state (EOS) [12] was selected. Platform B mainly processes gas and light liquid hydrocarbons, and the Soave-Redlich-Kwong EOS [13] was used. The process simulations of Platforms A and C were carried out with Aspen HYSYS [14] version 7.3. Platform D was simulated with Aspen Plus [15] version 7.2 using the Peng-Robinson EOS and the Non-Random Two Liquid model [16], with the exception of the glycol dehydration system that was simulated using the glycol property package of Aspen HYSYS.

The test manifold was merged together with the 1st stage separator in the simulations of Platforms A and B, while it was included as an independent separator in the simulations of Platforms C and D. Crude oil mixtures contain a large variety of chemical compounds, from hydrocarbons such as light alkanes and heavy aromatics, to impurities such as nickel and vanadium. Detailed compositional analyses of these mixtures are rarely carried out, and crude oils are thus modelled as mixtures of known and unknown, named hypothetical components. Light- and medium-weight hydrocarbons are represented by known components such as light alkanes and alkenes. On the contrary, the components forming the heavy fractions of the crude oil are not modelled individually, but are lumped into the fictive groups of components. A given hypothetical component corresponds therefore to several real components, and displays the thermophysical and chemical properties of a given fraction of the crude oil. In this work, the hypothetical properties were obtained from the operators for the Platforms A, B and C, while they were derived from crude oil assays and measurements for Platform D. The numerical tolerance limits of the process models were set so that the relative deviations between in and out flows of the systems were smaller than $2 \cdot 10^{-5}$ both for mass and energy for all four platforms. 


\subsection{Exergy analysis}

\subsubsection{Exergy accounting}

An exergy accounting was performed to identify the sources of thermodynamic inefficiencies in the four cases investigated. The exergy of a stream of matter is defined as the maximum theoretical work obtainable when the stream of matter interacts with the environment to reach equilibrium. This maximum theoretical work is obtained when all processes involved are reversible.Internal irreversibilities, that take place in all real processes, are responsible for exergy destruction in the oil and gas processing units. The exergy destruction can be calculated from an exergy balance [6,7]. For an open control volume in steady-state conditions, the exergy destruction rate, $\dot{E}_{\mathrm{d}}$, is defined as the difference between the rates of exergy entering and leaving a system:

$$
\dot{E}_{\mathrm{d}}=\dot{E}_{Q}+\dot{E}_{W}+\sum \dot{m}_{\text {in }} e_{\text {in }}-\sum \dot{m}_{\text {out }} e_{\text {out }}
$$

where $\dot{E}_{W}$ and $\dot{E}_{Q}$ are the rates of exergy accompanying work and heat entering the system. For simplicity we name these variables power and heat exergy in the rest of this study. The symbols $\dot{m}$ and $e$ represent the mass flow rate and the specific exergy of the stream of matter. Out of the exergy streams leaving the system, some streams are not useful, and is therefore discharged to the environment. Such streams can be identified as exergy losses.

\subsubsection{Exergy transfer}

The exergy transported with a material stream, $e$, can be expressed as the sum of its kinetic, $e^{\text {kin }}$, potential, $e^{\text {pot }}$, physical, $e^{\text {ph }}$, and chemical components, $e^{\text {ch }}[6]$ :

$$
e=e^{\mathrm{kin}}+e^{\mathrm{pot}}+e^{\mathrm{ph}}+e^{\mathrm{ch}}
$$

The specific physical exergy accounts for differences in temperature and pressure with the ambient temperature and pressure $\left(T_{0}, p_{0}\right)$ without changes in chemical composition. It is defined as:

$$
e^{\mathrm{ph}}=\left(h-h_{0}\right)-T_{0}\left(s-s_{0}\right)
$$

where $h$ and $s$ are the specific enthalpy and entropy calculated at the stream conditions and $h_{0}$ and $s_{0}$ at ambient temperature, $T_{0}$, and pressure, $p_{0}$. The specific chemical exergy accounts for differences in chemical composition with a reference environment and can be expressed as:

$$
e_{\text {mix }}^{\mathrm{ch}}=\underbrace{\sum_{i} x_{i} e_{i}^{\mathrm{ch}}}_{\mathrm{I}}+\underbrace{h_{0}-\sum_{i} x_{i} h_{i, 0}-T_{0}\left(s_{0}-\sum_{i} x_{i} s_{i, 0}\right)}_{\text {II }}=\underbrace{\sum_{i} x_{i} e_{i, \text { mix }}^{\mathrm{ch}}}_{\mathrm{III}}
$$

where term I represents the chemical exergy of the pure components, with $x_{i}$ the mass fraction and $e_{i}^{\text {ch }}$ the specific chemical exergy. Term II corresponds to the decrease of chemical exergy due to mixing effects, with $h_{i, 0}$ the enthalpy of pure component $i$ at ambient conditions, and $s_{i, 0}$ the corresponding entropy. Term III denotes the chemical exergy of the components in the mixture, with $e_{i, \text { mix }}^{\text {ch }}$ the specific chemical exergy of component $i$ in the mixture. The specific potential and kinetic exergies are equal to the potential and kinetic energies, respectively.

Exergy transferred as work (e.g. electric or mechanical work) is equal to the amount of work:

$$
\dot{E}_{W}=\dot{W}
$$

and exergy transferred as heat is determined by the Carnot efficiency, and is for temperatures above the ambient given by:

$$
\dot{E}_{Q}=\left(1-\frac{T_{0}}{T}\right) \dot{Q}
$$

The symbol $\dot{W}$ denotes work transfer and $\dot{Q}$ denotes transfer of thermal energy. 


\subsubsection{Calculation details}

The ambient pressure and temperature used in the calculation of physical exergy were $1 \mathrm{~atm}$ and $8{ }^{\circ} \mathrm{C}$, which is the average air temperature for the North Sea [17]. The chemical exergy of the pure components were taken as presented by Szargut [18] for the real chemical components. They are calculated following the method and correlations of Rivero [19] for the hypothetical components. Potential and kinetic exergy were assumed negligible in comparison with chemical and physical exergy in the present cases.

The control volume chosen for the exergy analysis on the four platforms includes the process modules shown in Fig. 1, with the components presented in Figs. A.7-A.10. The exergy destruction taking place in the heaters in Platforms B and C is assigned to the separation sub-systems, as the heating demand results from the temperature requirements in that section. The following sub-systems are not considered in this work, as they are not part of the processing plant as such, or contribute only to a minor extent to the total exergy destruction of the plant.

- The seawater lift, which includes the pumps required to lift the seawater on-site and to bring it to the pressure of the cooling water distribution system;

- The cooling medium system;

- The pilot flares and flare headers, where the unusable gas, released by pressure relief valves in several parts of the plant (e.g. separation and fuel gas sub-systems), is burnt off with air and rejected to the atmosphere;

- The produced water treatment, where chemicals such as biocides are mixed with produced water to ease separation with impurities;

- The gas lift, where the pressure of the gas streams is decreased to match the wellhead pressure and ease petroleum production.

In the present work, the term exergy destruction refers to the irreversibilities taking place within the control volume under study (internal irreversibilities). The term exergy losses refers to the irreversibilities outside this control volume, i.e. the ones taking place when waste exergy streams are dissipated to the environment.

For instance, the flare headers are considered as a part of the utility plant of an oil and gas platform. They are therefore not included in the control volume and all the chemical exergy in flared gas is counted as a loss. In the case of the coolers, the irreversibilities caused by the pressure drops on the gas and water side, as well as with heat transfer, are accounted as exergy destruction. The increase in temperature-based exergy on the cooling medium side is accounted as an exergy loss.

\section{Results}

The exergy input of the oil and gas processing plants, as well as the useful and lost exergy outputs, are given in Table 5. The exergy input consists of the exergy flowing with the well streams, the imported gas, and the heat and power exergies. The useful exergy output includes the exergy flowing with the export streams, gas for injection and lift, and fuel gas. The useful exergy output corresponds to $99.5 \%-99.8 \%$ of the exergy input. Such values are often referred to as the total exergy efficiencies. The exergy flows associated with the heat and power inputs to the processing plants are $0.05 \%-1.8 \%$ of the magnitude of the exported exergy flows.

The fuel gas is counted as useful output, even though it is not an exported product, because the focus of this study is the processing plants, and not the overall platforms. The fuel gas exergy represents $0.3 \%-8 \%$ of the exported exergy. The fuel gas is consumed to produce power for the drilling modules (where the loads vary significantly from day to day) and for the living quarter, as well as heat and power for the processing plants.

The main sources of exergy losses on the four studied platforms include the discharge of produced water, the release of flared and vented gases to the atmosphere, and the rejection of cooling water to the sea. 
The exact amount of exergy losses with flared and vented gases varies from day to day, as gas flaring is not practiced continuously and is subject to significant variations over days. For the days we study, the chemical exergy of the flared gases are significant at Platforms A and D, while exergy losses with produced water are significant in the cases of Platforms $\mathrm{C}$ and D.

Table 5: Exergy flows on the studied platforms, expressed in MW. For exergy flows related to material streams, the corresponding stream numbers from Fig. 1 are given.

\begin{tabular}{|c|c|c|c|c|c|}
\hline & $\begin{array}{l}\text { Stream } \\
\text { number }\end{array}$ & Platform A & Platform B & Platform C & Platform D \\
\hline \multicolumn{6}{|l|}{ Input flows } \\
\hline Well streams, total exergy & 1 & $5.8 \cdot 10^{3}$ & $11 \cdot 10^{3}$ & $15 \cdot 10^{3}$ & $3.8 \cdot 10^{3}$ \\
\hline Gas import, total exergy & 9 & - & - & $1.8 \cdot 10^{3}$ & - \\
\hline Power exergy input & - & 25 & 5.5 & 30 & 17 \\
\hline Heat exergy $\operatorname{input}^{a}$ & - & - & 0.28 & 6.9 & 1.8 \\
\hline \multicolumn{6}{|l|}{ Output flows, useful } \\
\hline Exported oil/condensate, total exergy & $4+6$ & $1.4 \cdot 10^{3}$ & $2.4 \cdot 10^{3}$ & $13 \cdot 10^{3}$ & $2.8 \cdot 10^{3}$ \\
\hline Exported gas, total exergy & 5 & - & $8.6 \cdot 10^{3}$ & - & $0.2 \cdot 10^{3}$ \\
\hline Gas injection and lift, total exergy & 5 & $4.3 \cdot 10^{3}$ & - & $4.3 \cdot 10^{3}$ & $0.8 \cdot 10^{3}$ \\
\hline Fuel gas, total exergy & 8 & 110 & 30 & 110 & 90 \\
\hline \multicolumn{6}{|l|}{ Output flows, lost } \\
\hline Produced water, chemical exergy & 7 & 0.94 & 0.17 & 3.6 & 16 \\
\hline Produced water, physical exergy & 7 & 0.54 & 0.14 & 2.0 & 6.1 \\
\hline Flared gas, chemical exergy & - & 5.0 & 1.3 & 0 & 4.7 \\
\hline Flared gas, physical exergy & - & $\leq 0.03$ & $\leq 0.01$ & 0 & $\leq 0.2$ \\
\hline Exergy leaving with cooling medium ${ }^{b}$ & - & 3.2 & 4.5 & 1.8 & 0.7 \\
\hline
\end{tabular}

${ }^{a}$ Both heat from the utilities and from heat integration between process streams.

${ }^{b}$ The temperature-based exergy received by the cooling medium.

The power and heat exergy, which are consumed in each subsystem for the four platforms, are presented in absolute numbers and per oil equivalent (o.e.) in Figs. 2 and 3, respectively. The unit oil equivalent is used by oil and gas companies as a way to present into a single measure the production of oil, gas and condensate. It is considered that 1 unit of volume of oil has roughly the same energy content as 1 unit of volume of condensate, or as 1000 units of volume of gas. The production manifolds are not included in Figs. 2 and 3, because no heat or power exergy is consumed there on any of the platforms, since the only processes taking place in the manifolds are mixing and throttling. For the remaining subsystems it is shown that:

- Power is mainly used for compression in the recompression sections, gas treatment sections and oil/condensate sections.

- On Platform D a significant amount of power is also used for increasing the seawater pressure for further injection.

- No power is required in the gas treatment section on Platform B, at the difference of the three other platforms, because the feed pressure $\left(p_{1}\right)$ at the inlet of the separation subsystem is high enough to meet the export specifications $\left(p_{5}\right)$.

- In the separation section on Platform C, approximately half of the exergy used for crude oil heating comes from heat integration with other product streams, while the other half comes from waste heat from the power turbines.

- The heating demand of the gas treatment and oil/condensate treatment sections on Platform D (in the dehydration processes) is met by recovering waste heat from the power turbines, electrical heating, and to a minor extent by heat integration. 
- Power used for heating in the fuel gas systems is less than $1 \%$ of the total power consumption for each of the platforms.

- Power and heat exergy consumed per oil equivalent is highest for Platform A, followed by Platform $\mathrm{D}$, while it is relatively small for Platforms B and C.

- The power exergy consumed per oil equivalent is particularly high in the gas treatment section on Platform A with $520 \mathrm{MJ} /$ o.e.



Figure 2: Power and heat exergy consumed in each subsystem for the studied platforms (Platforms A-D). The production manifolds are not included, since no power and heat exergy is consumed there. The thermal energy labelled 'waste heat' is from a heating medium that is heated with waste heat from the power turbines. The thermal energy labelled 'heat integration' is from heat integration with other process streams.

In Fig. 4 exergy destruction in each subsystem for each of the platforms are given and in Fig. 5 the same values are given as percentage for each platform. In general, the highest contributions to exergy destruction are due to:

- throttling in production manifolds and separation trains;

- irreversibilities in coolers;

- inefficiencies in compressors and anti-surge recycling.

A more detailed investigation of Fig. 5 shows the following about the locations and sources of exergy destruction on the four platforms:

- Exergy destruction in production manifolds represents 10-24\% of the total exergy destruction at the four platforms.

- Exergy destruction due to throttling in separation trains accounts for $2-12 \%$.

- Exergy destroyed in compressors amounts to $28-40 \%$, with the exception of Platform B where it amounts to only $13 \%$. 


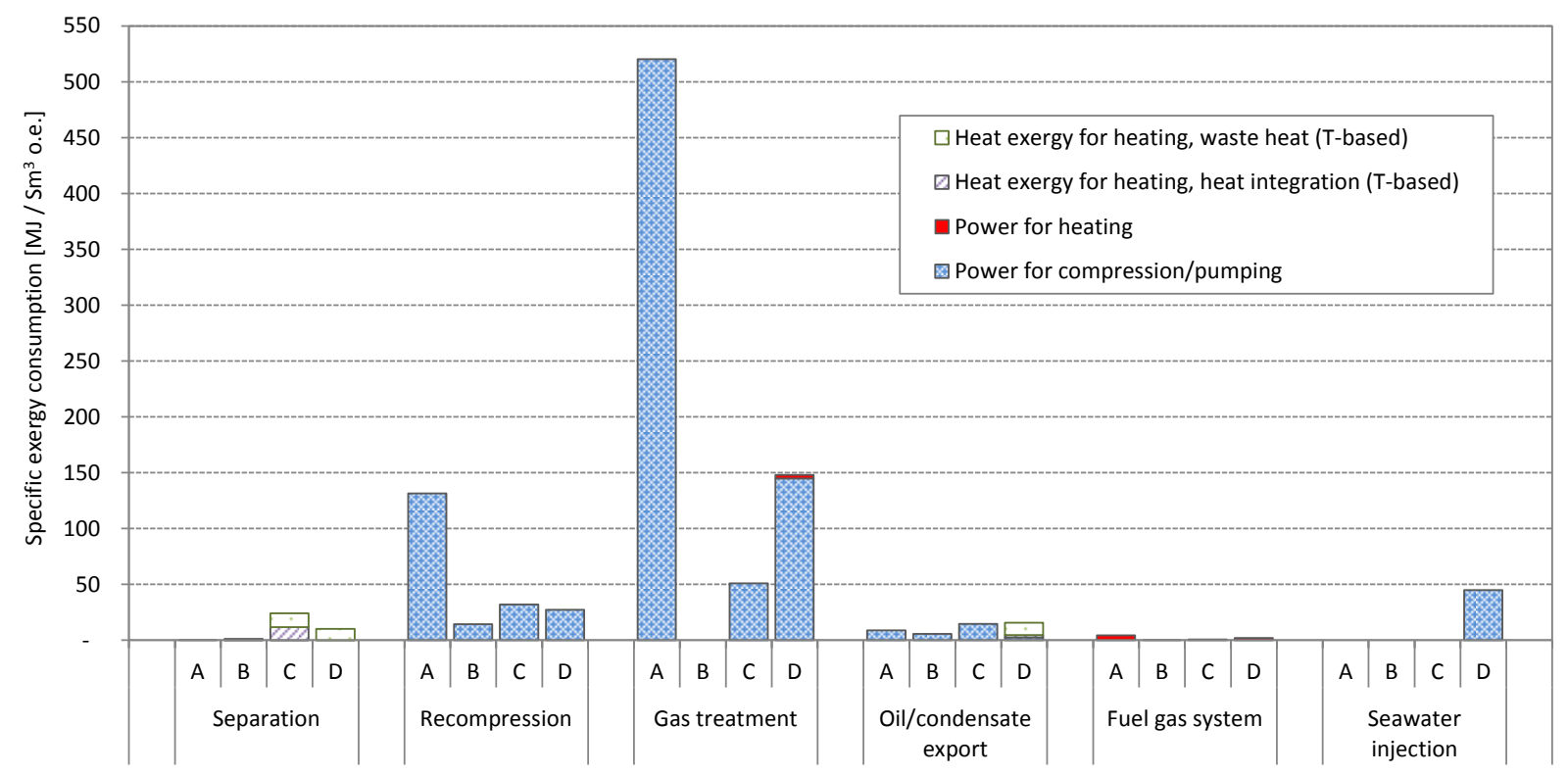

Figure 3: Power and heat exergy consumed per exported oil equivalent (o.e.) in each subsystem for the studied platforms (Platforms A-D). The production manifolds are not included, since no power and heat exergy is consumed there. The heat exergy labelled 'waste heat' is from a heating medium that is heated with waste heat from the power turbines. The thermal energy labelled 'heat integration' is from heat integration with other process streams.

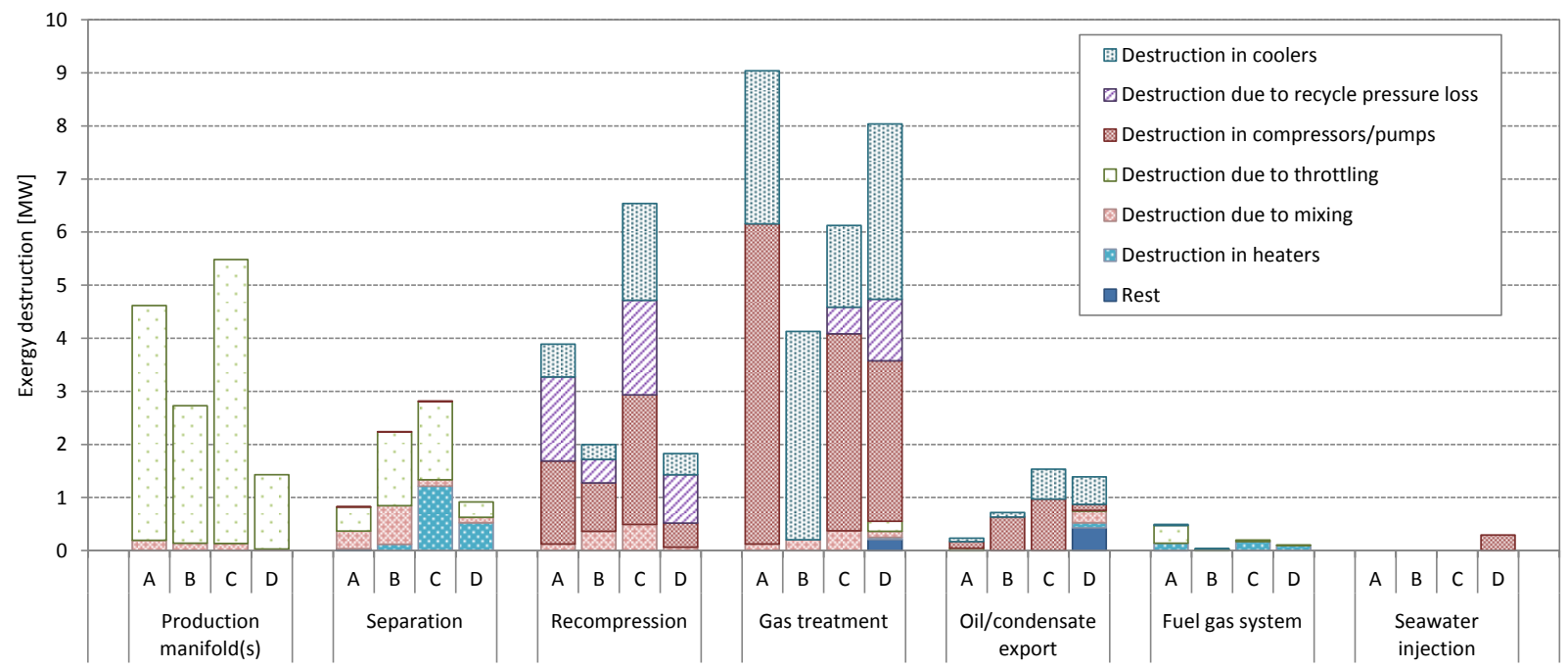

Figure 4: Exergy destruction in each subsystem for the studied platforms (Platforms A-D). The main sources of exergy destruction/loss in each subsystem are indicated with different colours, and smaller sources are lumped into 'rest'. The term 'rest' corresponds to minor contributions to the exergy destruction such as pressure drops in pipelines, distillation and regeneration columns.

- On Platform B, $33 \%$ is due to cooling in the gas treatment section.

- Exergy destruction due to pressure loss in recycled streams amounts to $4-15 \%$ for the four platforms.

- Exergy destruction in the crude oil heater makes up approximately $6 \%$ and $5 \%$ respectively for Plat- 


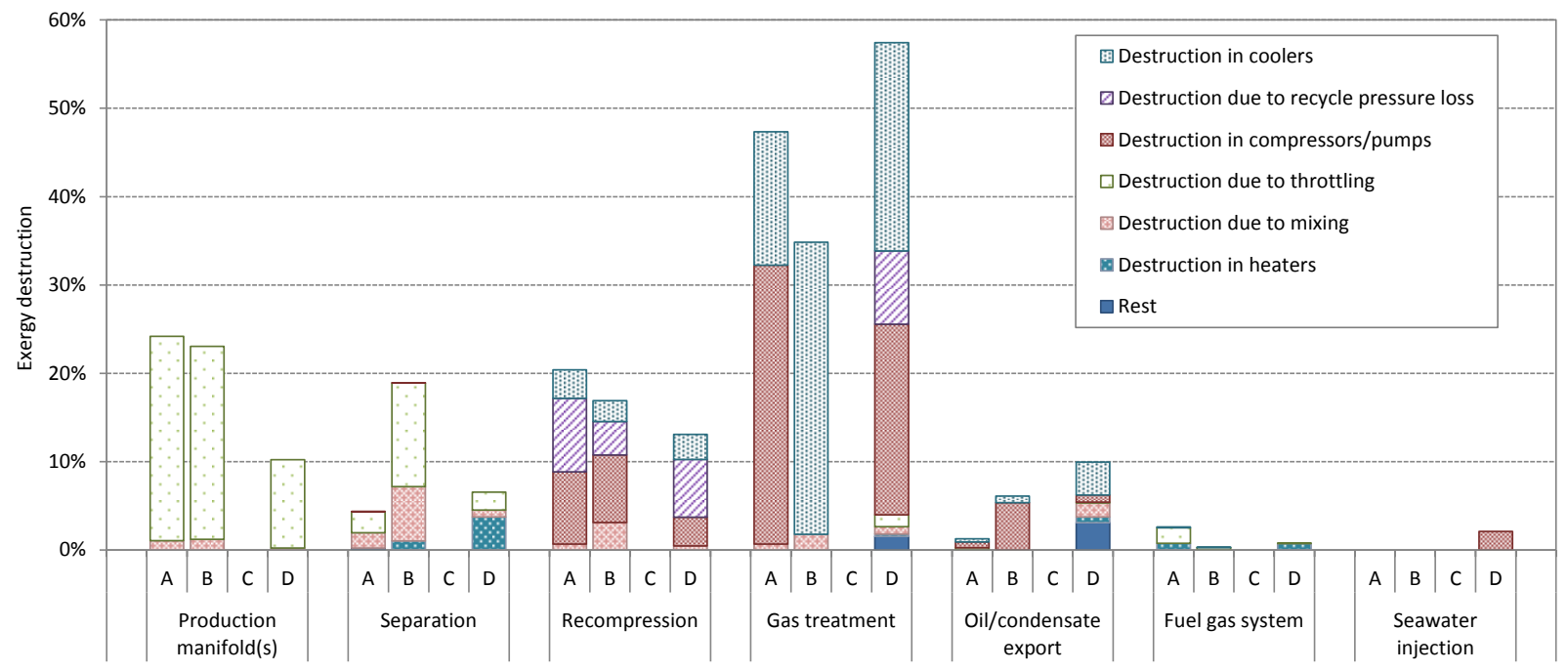

Figure 5: Percentage of exergy destruction in each subsystem for the studied platforms (Platforms A-D). The main sources of exergy destruction/loss in each subsystem are indicated with different colours, and smaller sources are lumped into 'rest'. The term 'rest' corresponds to minor contributions to the exergy destruction such as pressure drops in pipelines, distillation and regeneration columns.

\section{forms $\mathrm{C}$ and D.}

- The exergy destruction in the oil/condensate export system of Platform A accounts for 1\%, while for Platforms B-D it accounts for $6-10 \%$.

- Exergy destruction in the fuel gas, produced water handling and seawater injection systems are of minor importance compared to the other studied systems.

The exergy destroyed per exported oil equivalent in each subsystem for the four platforms are shown in Fig. 6. Platforms A and D have clearly more inefficiencies per oil equivalent than Platforms B and C. They are older than the other two platforms and have export flow rates that are low compared to their peak production. Platform A has a high gas-to-oil ratio (2800), injects gas and exports only oil. The injection of gas makes a high oil recovery from the reservoir possible but is responsible for considerable power consumption and exergy destruction:

- The large amount of gas that is not exported gives high exergy destruction per exported oil equivalent in the production manifold (125 MJ/o.e.).

- In the recompression train, recycling of gas to prevent compressor surging has led to almost constant flow rates, and thus exergy destruction, even if the amount of oil in the separation train has decreased.

- The high exergy destruction per exported oil equivalent in the gas treatment section (245 MJ/o.e.) is because here a significant amount of compression work is done to produce gas that is not exported but used for enhanced oil recovery.

Platform D has a low gas-to-oil ratio (230), uses gas and seawater for lift and injection, and exports oil, gas and condensate. The high exergy destruction per exported oil equivalent (178 MJ/o.e.) results from the large amount of power required to compress the gas. 


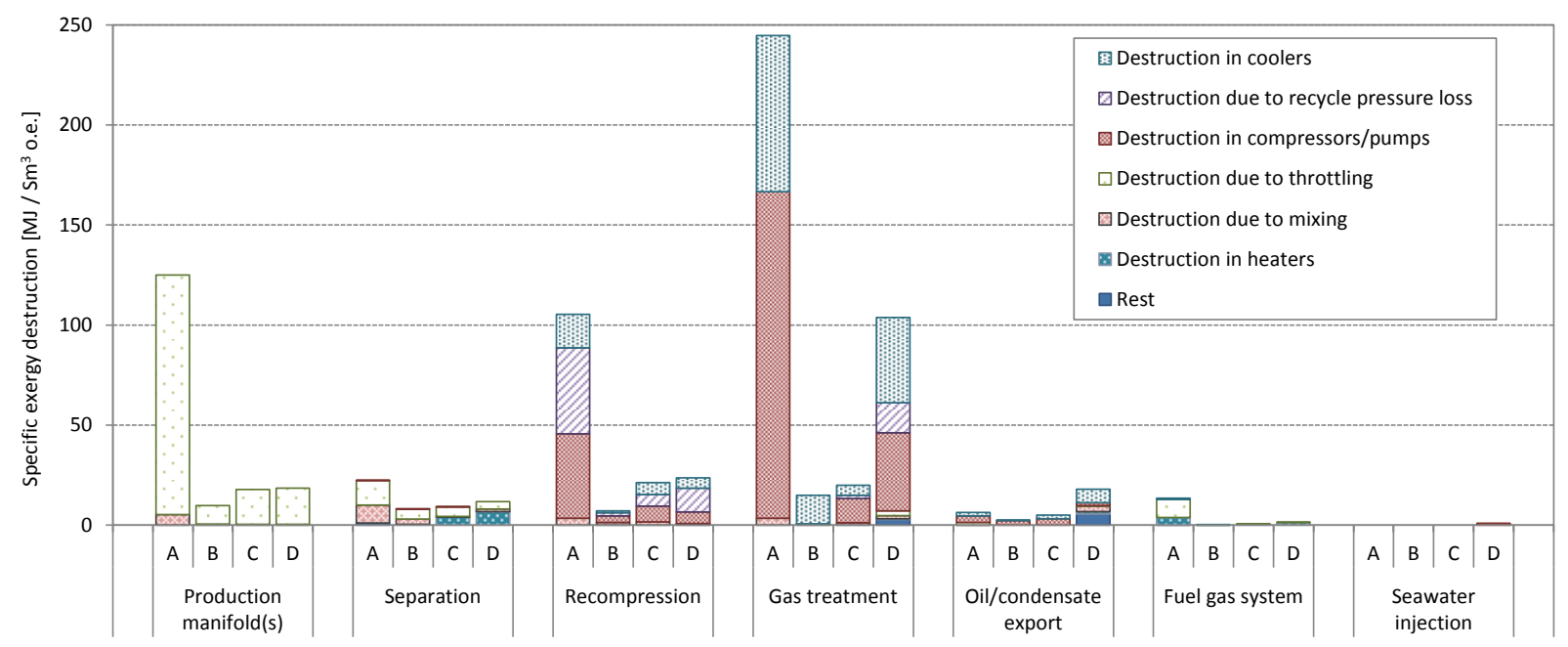

Figure 6: Exergy destruction per exported oil equivalent (o.e.) in each subsystem for the studied platforms (Platforms A-D). The main sources of exergy destruction/loss in each subsystem are indicated with different colours, and smaller sources are lumped into 'rest'. The term 'rest' corresponds to minor contributions to the exergy destruction such as pressure drops in pipelines, distillation and regeneration columns.

\section{Discussion}

\subsection{Accuracy}

The main results of this study are estimates for heat and power exergy consumption, exergy destruction and exergy losses. The accuracy of these results, i.e. the closeness to the true values, depends on the accuracy of the simulations and on the energy and exergy calculations. The following points may affect the accuracy: (i) the variations of the process variables throughout the day, (ii) measurement uncertainties, (iii) accuracy of the equations of state, (iv) accuracy of correlations used in calculation of chemical exergy and (v) selection of standard state for chemical exergy calculations.

There are natural variations in the feed compositions, temperatures, pressures and flow rates, which lead to variations also in other process variables throughout the system. However, steady-state conditions were assumed in the calculations. As described in Section 2.2, the measured values considered in the simulations for Platforms A, B and D were day-averaged, and this results in a levelling of inconsistencies due to lag effects of the system. In the case of Platform $\mathrm{C}$, the measured values were taken at a specific point of time so for this platform there is a higher possibility for inconsistent data. All four platforms are simulated on days with stable conditions, and this both limits lag effects and gives small standard deviations over the day.

An overview of measurement uncertainties is given in Table 6 . The authorities have set requirements for the uncertainties of fiscal measurements, e.g. export flow rates and fuel gas consumption. The measurement uncertainties for such variables were assumed to be equal to the limits set in the requirements. The values for the measurement uncertainties for other process variables were assumed based on guidelines set by the oil company, discussions with the operators and the authors own experiences. In most cases, the measurement uncertainties were larger than the standard deviations of the variables over the day, so the latter were therefore not taken into consideration in this study.

The Peng-Robinson [12] and the Soave-Redlich-Kwong [13] equations of state (EOS) were used to calculate the enthalpies and entropies of each stream. Both were conceived to estimate the vapour-liquid equilibrium properties and fugacities of hydrocarbon mixtures, and they are widely used for modelling petroleum processes. The Soave-Redlich-Kwong EOS was initially designed to describe the behaviour of small and non-polar molecules in vapour phase, making it particularly suitable for modelling gas processes. However, it was inaccurate for calculations of hydrocarbon properties in liquid phase. This was improved in 
the Peng-Robinson EOS [20,21]. The Soave-Redlich-Kwong EOS was chosen for the simulations of Platform C, which mostly processes gas, and the Peng-Robinson EOS for the simulations of Platforms A, B and D.

For the calculation of heat and power exergy consumption and exergy losses, uncertainty originating from measurements and from the equation of state are most relevant. A detailed analysis of the impact of these points were performed for Platform A [9]. Uncertainty originating from the equation of state was evaluated by comparing values obtained for methane from the equation of state used in the simulation, with values obtained from a presumably more accurate equation of state. The total uncertainties originating from these two error sources were lower than $10 \%$ for the power consumption and exergy destruction in the production manifolds, recompression and gas treatment sections. The uncertainties for the separation and export sections were higher (Table 7). For all four platforms, the processes are similar, the measurements are of the same type, and the same or similar equations of state were used as for Platform A. These points suggest that the uncertainties of the calculated heat and power consumption and exergy destruction for Platforms B-D are of the same magnitude as for Platform A.

Table 6: Measurement uncertainty assumed at 95\% confidence level for process variables, expressed in $\%$.

\begin{tabular}{lr}
\hline Process variable & Uncertainty \\
\hline Pressure & 1.0 \\
Temperature & $1.0{ }^{\circ} \mathrm{C}$ \\
Electric power & 2 \\
Oil/condensate export flow rate & 0.3 \\
Gas export flow rate & 1.0 \\
Fuel gas flow rate & 1.8 \\
Flare gas flow rate & 5 \\
Other flow rates & 10 \\
\hline
\end{tabular}

Table 7: Uncertainty of total power consumption and total exergy destruction for Platform A [9], expressed in \%.

\begin{tabular}{lrr}
\hline & Power & Exergy destruction \\
\hline Production manifold & - & 9 \\
Separation & 15 & 25 \\
Export section & 47 & $40^{a}$ \\
Recompression & 0.6 & 5 \\
Gas treatment & 1 & 5 \\
Fuel gas system & 1 & 1 \\
\hline
\end{tabular}

${ }^{a}$ Misprint in [9]. For exergy destruction in export section, the uncertainty should be $100 \mathrm{~kW}$.

The method of Rivero [19] was used to calculate the chemical exergy of hypothetical components, based on the lower heating value and on the elemental composition of each crude oil fraction. Szargut presented a similar expression, which takes fewer elements into account and this equation is claimed to have a mean accuracy of $0.5 \%$ [18]. The petroleum correlations used to estimate the lower heating value have an accuracy of $1 \%$ [22]. The correlations are based on the elemental composition and the specific gravity of each crude oil fraction, and these properties are not exactly known. Petroleum assays for blends containing the specific crude oils were used instead, and this gives additional error to the exergy of the hypothetical components.

The reference environment of Szargut [18] was used in this study. It is worth noticing that the model of Kotas [6], which is based on a previous model of Szargut, predicts a standard chemical exergy three times larger for water, but displays similar values for hydrocarbon compounds. However, the model of Kotas has a reference atmosphere with a relative humidity of $28 \%$, while the relative humidity is $70 \%$ in the model of Szargut. Since the platforms are located offshore, the model of Szargut is considered to be most realistic.

The accuracy of the calculated exergy of waste streams (exergy losses), as well as the exergy of feed and export streams, do mainly depend on the calculation of chemical exergy of the hypothetical components, and on the uncertainty of the exported flow rates. The exergy losses associated with produced water does in addition have a strong dependency on the choice of reference environment. 


\subsection{Suggestion of process improvements}

The four platforms compared within this study are of the North Sea platform type. They illustrate the diversity among these facilities, with production of heavy and viscous oil to condensate and gas, and with different product specifications, reservoir conditions, and operating strategies. The mapping of the thermodynamic irreversibilities shows where exergy is destroyed in the system and hints therefore to process route improvements.

\subsubsection{Production manifold}

Significant quantities of exergy are destroyed in the production manifold in any case. It is therefore expected that most North Sea platforms present this behaviour, and this is supported by the findings of the generic analysis conducted by Nguyen et al. [10]. The two platforms where this exergy destruction is the lowest (Platforms B and D) are characterised by a small difference between the inlet pressures of the choke valves and of the 1st stage separators. The first one has the highest gas-to-oil ratio (3200), and condensategas separation can be started at a relatively high pressure $(120 \mathrm{bar})$. On the opposite, the second one has the lowest gas-to-oil ratio (230), but the highest water production $\left(1110 \mathrm{Sm}^{3} / \mathrm{h}\right)$. It is run at the end-life of the production field, and the pressure at the inlet of the production manifold has therefore decreased.

A first possibility for improving these systems is to design the production manifolds at several pressure levels, as done on some platforms. Gas can be recovered at higher pressures, meaning that a smaller amount of exergy is destroyed by throttling, and lower compression power is required. It would also limit mixing of well-streams with different compositions, and ease phase separation. As the reservoir pressure decreases with time, inflowing streams can be rerouted to another manifold when their pressure becomes lower. However, the selection of the number of manifolds, and of the pressure levels, is a compromise between the supplementary equipment cost (capital cost), the operating costs (smaller power demand and larger gas export) and the oil production (smaller liquid production).

Other possibilities are to integrate multiphase expanders, which would reduce the exergy destruction taking place in the expansion process and generate additional power, or multiphase ejectors that can use exergy in high pressure wells to increase production in depleted ones. However, the design of such equipment is a challenging task because the well-streams contain sand, hydrogen sulphides and other impurities, and this could cause corrosion and reduce the lifetime of these components.

The overall benefits of measures on production manifolds are linked to the development of the feed composition over time. High pressure gas contains more pressure-based exergy than high pressure liquid.

\subsubsection{Gas treatment}

The present comparison suggests that the gas treatment process often is the major exergy-destroying sub-system. It results from combined effects of the inefficiencies of the turbomachinery components, and of the temperature gap between the cooling water and hot gas streams. These trends were observed for all platforms where there was a need for gas compression, both with and without anti-surge recycling. This illustrates that designing and operating a highly efficient gas compression process is critical for reaching a high performance of the overall processing plant. However, it is challenging to maintain a high performance because the gas flow rates decrease with time, resulting in compressors run in off-design conditions. Svalheim $[2,3]$ and Bothamley [23] proposed various measures, such as re-wheeling the compressors when large amounts of gas must be recycled to prevent surge. The integration of several but parallel trains would also result in higher energy savings, since varying flow rates can be handled by closing or opening parallel trains, and the compressors will be run for a longer period near their nominal point.

The exergy destruction taking place in the coolers placed before the compressors is partly caused by the anti-surge recycling, as larger gas flow rates need to be cooled before being recompressed. Smaller amounts of exergy may be destroyed with a better match of the water and gas flow rates and temperatures. The exergy discharged from the gas streams may be recovered, although it may be difficult to recover heat at these temperature levels $\left(30\right.$ to $\left.150{ }^{\circ} \mathrm{C}\right)$. Further integration with the heating systems present on the facilities may be investigated. 


\subsubsection{Process-utility integration}

The interactions between the utility system and the processing plant should be investigated in further details. A comparison with the Brazilian platform investigated by Oliveira and Van Hombeeck [8] shows the differences across platforms located in different oil regions. On the four North Sea platforms studied in this work, the heating demand was limited, and waste heat from the exhaust gases was enough to cover it. The gas turbines were designed to provide the required electrical power, but a large amount of excess heat is discharged into the environment, as it is recovered only to a moderate extent. On the opposite, on the Brazilian platform, the oil separation process has a significant heating demand, and recovering waste heat from the gas turbines was not sufficient. A furnace was therefore complementing the heat recovery system.

The heating demand depends, among other factors, on (i) the initial feed temperature, which is lower in the Brazilian Gulf than in the North Sea, (ii) the viscosity of the crude oil (iii) the content of mediumweight hydrocarbons, which is much higher for the oil extracted on Platform D than conventional light oil, (iv) the integration of processes such as $\mathrm{CO}_{2}$-capture by chemical absorption, glycol dehydration and condensate fractionation. These energy efficiency measures are discussed in the works of Kloster $[4,5]$ and of Nguyen et al. [10]. Replacing conventional combustion technologies to combined cycles may be one of the most significant measures for improving the efficiency of oil and gas platforms. Cogeneration technologies together with a high level of process integration, may be relevant for platforms with a high heat demand. The integration of bottoming cycles would improve the efficiency of the complete system, at the expense of higher capital costs due to higher space requirements. Such solutions are already in use on other North Sea installations [24].

\subsubsection{Flaring, cooling water and produced water}

Losses with flaring vary from day to day, but for some platforms the total amount of exergy dissipated with these gas losses can be significant throughout the year. Such losses can be reduced with the use of gas recovery systems, as already done on Platform C.

Little can be done to recover exergy from the produced and cooling water flows, since their chemical exergy is hardly usable, and their temperature is relatively low $\left(50-75{ }^{\circ} \mathrm{C}\right)$. Kloster [4] suggested to use the produced water extracted along with oil and gas instead of treated seawater or to re-use the cooling water for enhanced oil recovery water injection, as done on some platforms, to reduce the pumping and water demands. However, the hydrocarbon content of the wastewater may be problematic, as it could cause plugging, and re-using the produced water for injection is only possible for platforms operated on fields with a high water-to-oil ratio.

\subsection{Significance and limitations}

We have mapped the exergy destruction and losses in the oil and gas processing plants of four oil and gas platforms. The present findings are in accordance with the results of Svalheim and King [2], who stated that the gas compression step is the most energy-demanding steps. They can also be compared to the previous findings of Bothamley [23] who focused on the variety of offshore processing options in different oil regions. The findings of this paper may be used for estimating qualitatively the locations and extents of thermodynamic irreversibilities on North Sea oil and gas platforms, although caution should be exercised when other design setups are considered, or if the compositions of the well-streams differ strongly.

Moreover, the four platforms present significant differences among each other: the well-fluid composition differs from one facility to another, different products are exported and gas is sometimes used for lift or injection, and processes such as condensate treatment and gas dehydration are not always installed. A direct comparison is therefore made difficult. However, it should be noted that, although significant differences can be found between the four platforms, general trends can be observed. Significant exergy destruction takes place in the compressors and coolers in any case, and the gas recirculation to prevent surge has a significant impact for platforms with decreasing oil and gas production. The results depend on factors such as (i) the efficiency and the control strategies of the turbo-machinery components (ii) the integration of additional subsystems and (iii) the outlet specifications of the processing plant.

The integration of gas dehydration has little impact on the total exergy destruction of the platform. The irreversibilities taking place in the glycol absorber and in the regenerator are small in comparison to the 
ones taking place in the compressors and coolers, because of the small flow rate of tri-ethylene glycol. The integration of an additional condensate treatment section results in a smaller power consumption, compared to the case where no separate section is integrated [25].

Finally, the differences between the platforms analysed in this study and the Brazilian case shows that caution should be exercised when extending the present conclusions to platforms in other regions of the world. This suggests that each oil platform should be assessed individually, to pinpoint major sources of exergy destruction on that specific facility.

\section{Conclusion}

Exergy analyses were performed on the oil and gas processing plants on four North Sea oil and gas platforms, which differ by their operating conditions and strategies. The comparison of the sources to exergy destruction and exergy losses illustrated the large exergy destruction associated with the gas treatment and production manifold systems, ranging above $27 \%$ and $10 \%$, respectively. The fuel gas and seawater injection processes represent less than $3 \%$ each in every case. For two of the platforms the exergy losses due to flaring were significant.

However, the contributions of the recompression, separation and oil export sections vary across the different platforms. Although the precise values of the exergy destruction rates differ from one platform to another, the results indicate that the largest rooms for improvement lie in (i) gas compression systems, (ii) production manifolds, and (iii) flared gas recovery.

\section{Acknowledgements}

The motivation from Statoil's new-idea project of reducing $\mathrm{CO}_{2}$ emissions from offshore oil and gas platforms is essential to this study. The Faculty of Natural Sciences and Technology at the Norwegian University of Science and Technology is acknowledged for financial support, as well as the funding from the Norwegian Research Council through the Petromaks programme, within the project 2034/E30 led by Teknova.

\section{References}

[1] Statistics Norway . Emissions of greenhouse gases: Create your own tables and graphs. 2013. Http://www.ssb.no/emner/01/04/10/klimagassn/ [October 2013].

[2] Svalheim SM, King DC. Life of Field Energy Performance. In: Proceedings of the SPE Offshore Europe Conference. July; Aberdeen, United Kingdom: Society of Petroleum Engineers; 2003, p. 1-10 (Paper SPE 83993).

[3] Svalheim SM. Environmental Regulations and Measures on the Norwegian Continental Shelf. In: Proceedings of the SPE International Conference on Health, Safety and Environment in Oil and Gas Exploration and Production. Kuala Lumpur, Malaysia: Society of Petroleum Engineers; 2002, p. 1-10 (Paper SPE 73982).

[4] Kloster P. Energy Optimization on Offshore Installations with Emphasis on Offshore and Combined Cycle Plants. In: Proceedings of the Offshore Europe Conference. Aberdeen, United Kingdom: Society of Petroleum Engineers; 1999, p. 1-9 (Paper SPE 56964).

[5] Kloster P. Reduction of Emissions to Air Through Energy Optimisation on Offshore Installations. In: Proceedings of the SPE International Conference on Health, Safety, and the Environment in Oil and Gas Exploration and Production. Stavanger, Norway: Society of Petroleum Engineers; 2000, p. 1-7 (Paper SPE 61651).

[6] Kotas TJ. The Exergy Method of Thermal Plant Analysis. Malabar, USA: Krieger Publishing; 1995.

[7] Bejan A, Tsatsaronis G, Moran M. Thermal Design \& Optimization. New York, USA: John Wiley \& Sons; 1996.

[8] Oliveira Jr. SD, Van Hombeeck M. Exergy Analysis of Petroleum Separation Processes in Offshore Platforms. Energy Conversion and Management 1997;38(15-17):1577-84.

[9] Voldsund M, Ertesvåg IS, He W, Kjelstrup S. Exergy Analysis of the Oil and Gas Processing a Real Production Day on a North Sea Oil Platform. Energy 2013;55:716-27.

[10] Nguyen TV, Pierobon L, Elmegaard B, Haglind F, Breuhaus P, Voldsund M. Exergetic assessment of energy systems on North Sea oil and gas platforms. Energy 2013;-:1-14. doi:10.1016/j.energy.2013.03.011; Energy (in press).

[11] Jøssang K. Evaluation of a North Sea oil platform using exergy analysis. Master's thesis; Norwegian University of Science and Technology; 2013.

[12] Peng DY, Robinson DB. A New Two-Constant Equation of State. Industrial \& Engineering Chemistry Fundamentals $1976 ; 15(1): 59-64$. 
[13] Soave G. Equilibrium constants from a modified Redlich-Kwong equation of state. Chemical Engineering Science $1972 ; 27(6): 1197-203$

[14] Aspen Technology . Aspen Hysys 2004.2 囚- User Guide. Cambridge, USA: Aspen Technology; 2004.

[15] Aspen Technology . Aspen Plus - Modelling Petroleum Processes. Burlington, USA: Aspen Technology; 1999.

[16] Renon H, Prausnitz JM. Local compositions in thermodynamic excess functions for liquid mixtures. AIChE Journal $1968 ; 14(1): 135-44$

[17] Norwegian Meteorological Institute . Mean temperature - ordered report. http://eklima.met.no; 2012.

[18] Szargut J, Morris D, Steward F. Exergy analysis of thermal, chemical, and metallurgical processes. New York, USA: Hemisphere; 1988

[19] Rivero R, Rendon C, Monroy L. The Exergy of Crude Oil Mixtures and Petroleum Fractions: Calculation and Application. International Journal of Applied Thermodynamics 1999;2(3):115-23.

[20] Tsonopoulos C, Heidman J. From Redlich-Kwong to the present. Fluid phase equilibria 1985;24(1):1-23.

[21] Soave G. 20 years of Redlich-Kwong equation of state. Fluid Phase Equilibria 1993;82:345-59.

[22] Speight JG. Handbook of petroleum product analysis. Wiley; 2002.

[23] Bothamley M. Offshore Processing Options for Oil Platforms. In: Proceedings of the SPE Annual Technical Conference and Exhibition. Houston, USA: Society of Petroleum Engineers; 2004, p. 1-17 (Paper SPE 90325).

[24] Alveberg LJ, Melberg EV, editors. Facts 2013: The Norwegian Petroleum Sector. Ministry of Petroleum and Energy and Norwegian Petroleum Directorate; 2013.

[25] Li KJ. Use of a Fractionation Column in an Offshore Environment. In: Proceedings of the SPE Annual Technical Conference and Exhibition. New Orleans, USA: Society of Petroleum Engineers; 1996, p. 1-11 (Paper SPE 49121).

\section{Appendix A. Process Flowsheets}

The process flowsheets of each of the platforms are shown in Figs. A.7 - A.10. 


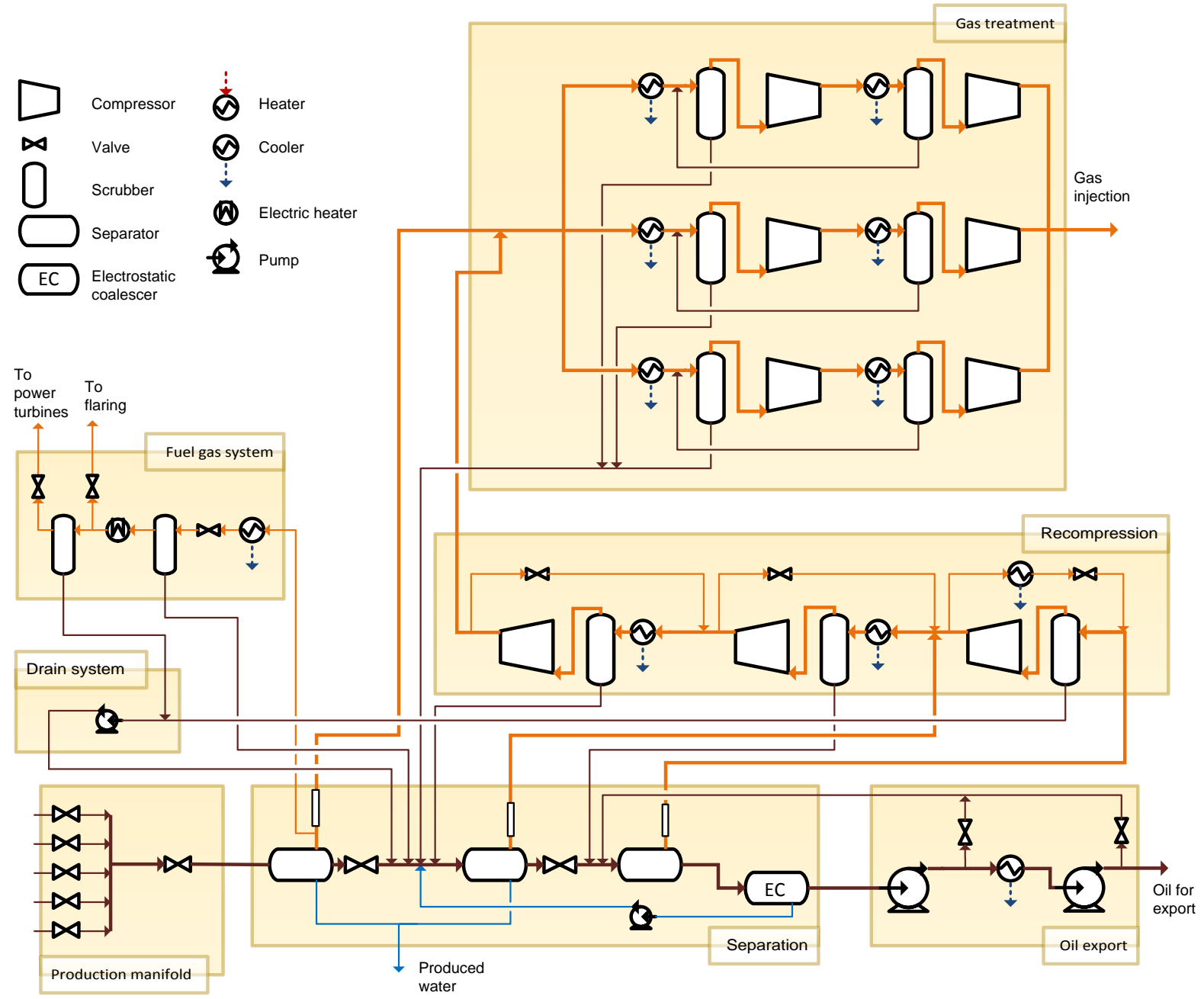

Figure A.7: Process flow diagram of the processing plant of Platform A. Gas streams are shown with orange arrows, water streams with blue arrows, and oil, condensate and mixed streams are shown with brown arrows. 


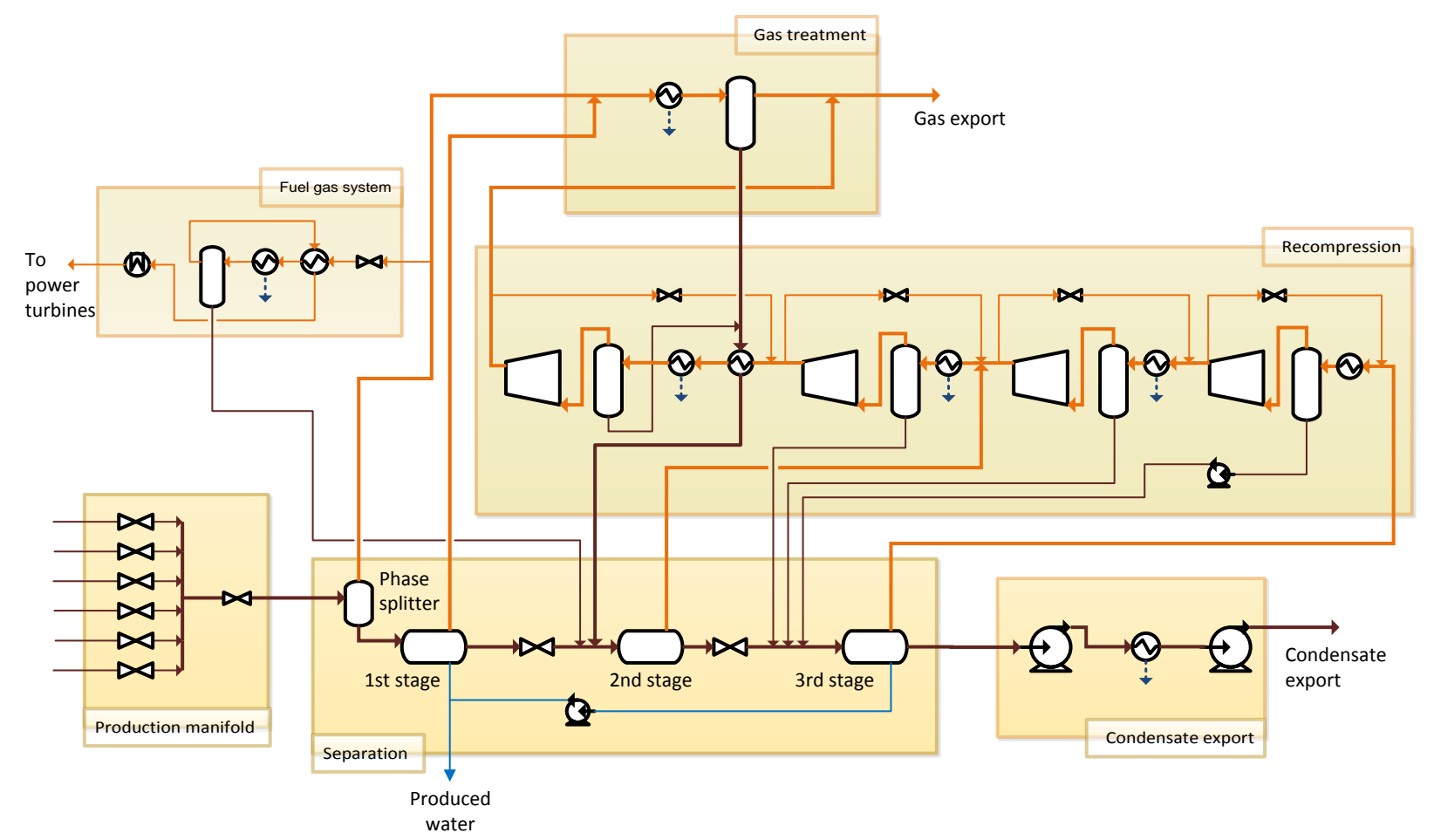

Figure A.8: Process flow diagram of the processing plant of Platform B. Gas streams are shown with orange arrows, water streams with blue arrows, and oil, condensate and mixed streams are shown with brown arrows. Symbol explanations can be found in Fig. A.7 


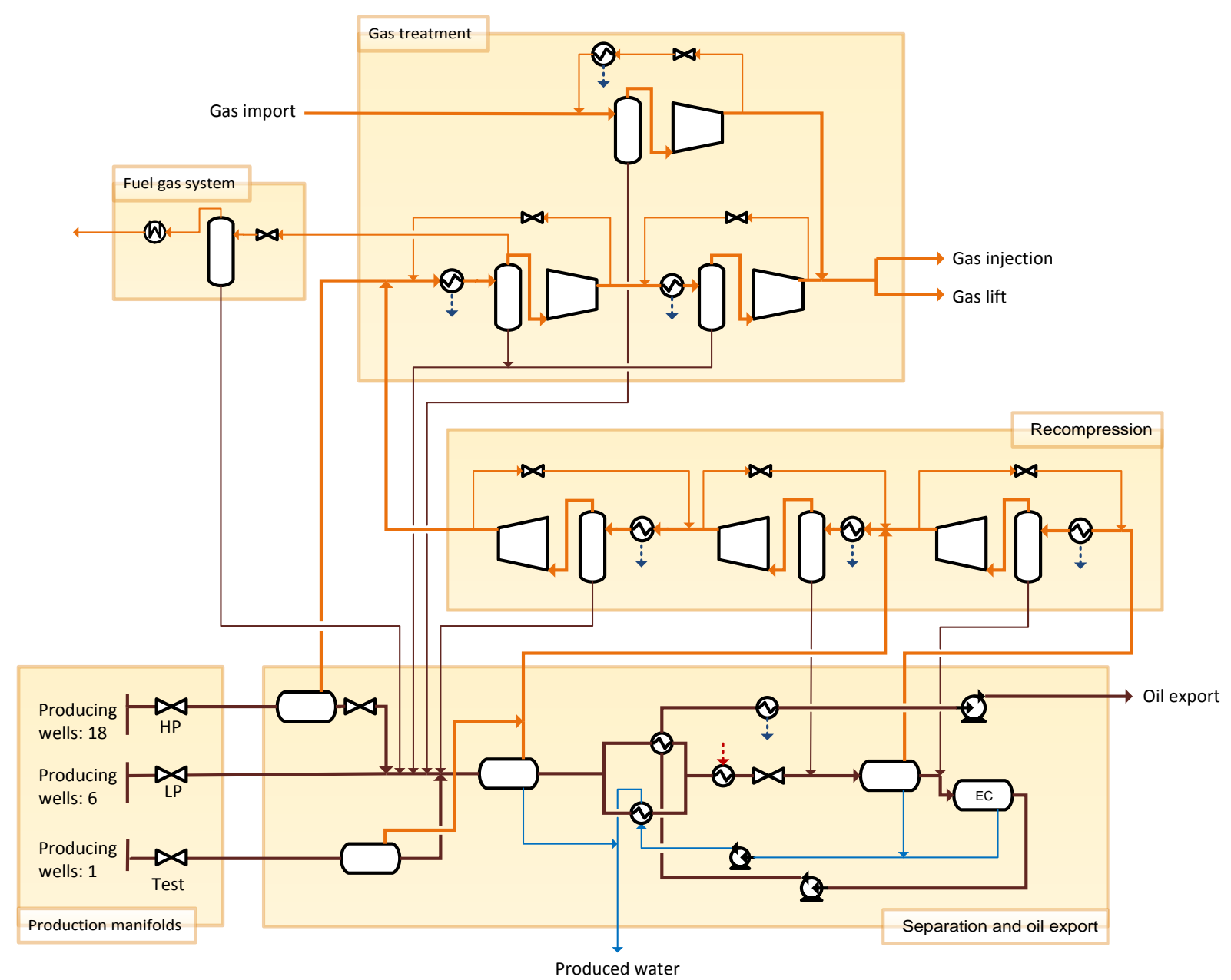

Figure A.9: Process flow diagram of the processing plant of Platform C. Gas streams are shown with orange arrows, water streams with blue arrows, and oil, condensate and mixed streams are shown with brown arrows. Symbol explanations can be found in Fig. A.7 
$\square$ Compressor \& Valve $\rightarrow$ Pump $\square$ Separator $\odot$ Heat exchanger 0 Scrubber ODegasser 目 Column $\square$ Kettle

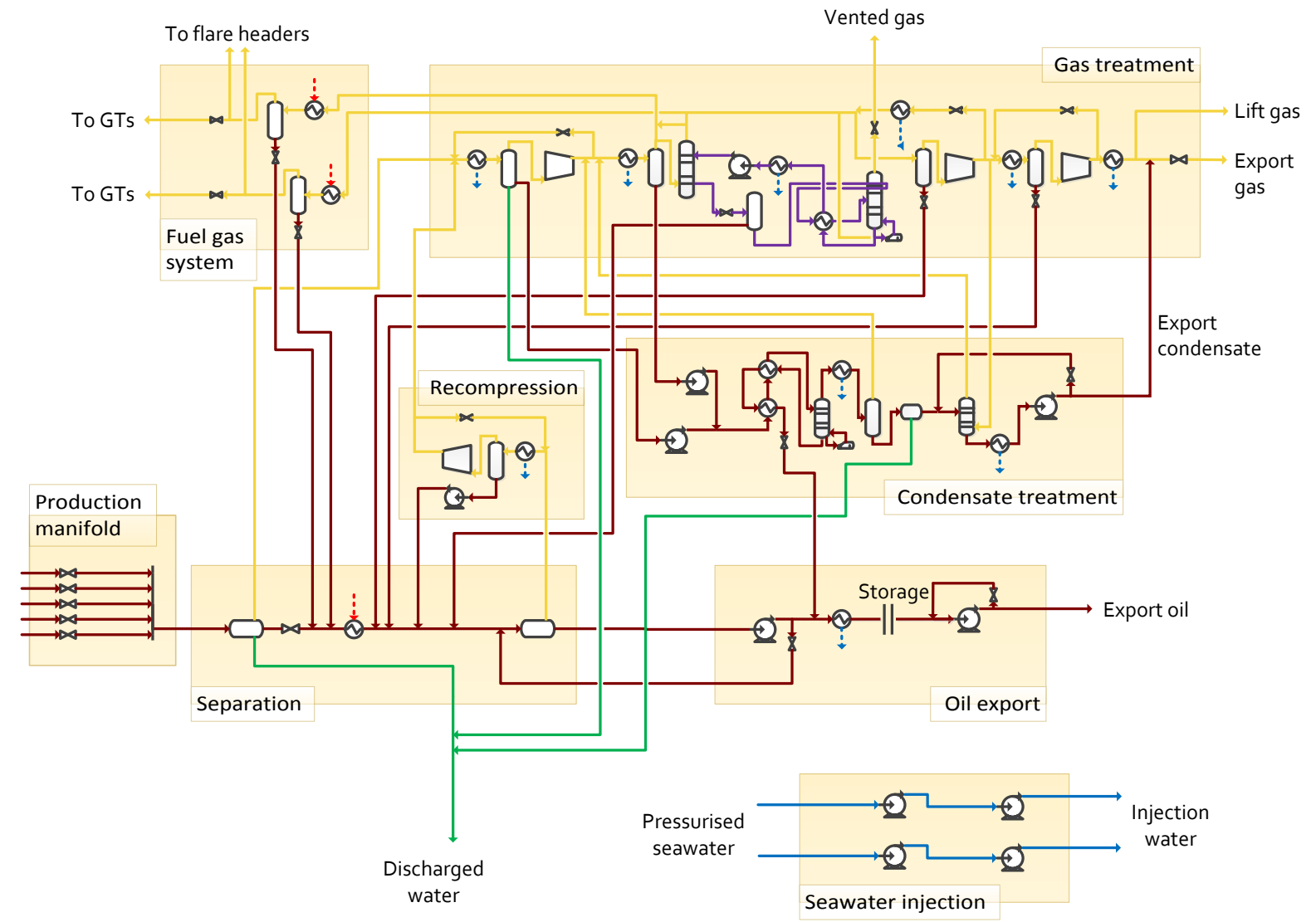

Figure A.10: Process flow diagram of the processing plant of Platform D. Gas streams are shown with orange arrows, water streams with blue arrows, glycol is shown with purple arrows, and oil, condensate and mixed streams are shown with brown arrows. 


\section{Supplementary information: Process modelling}

\section{Platform A}

All details on process data, except for the cooling water system, for Platform A can be found in Ref [9]. The process flowsheet is shown in Fig. A.11. Details for the cooling water system are found in Table A.8.

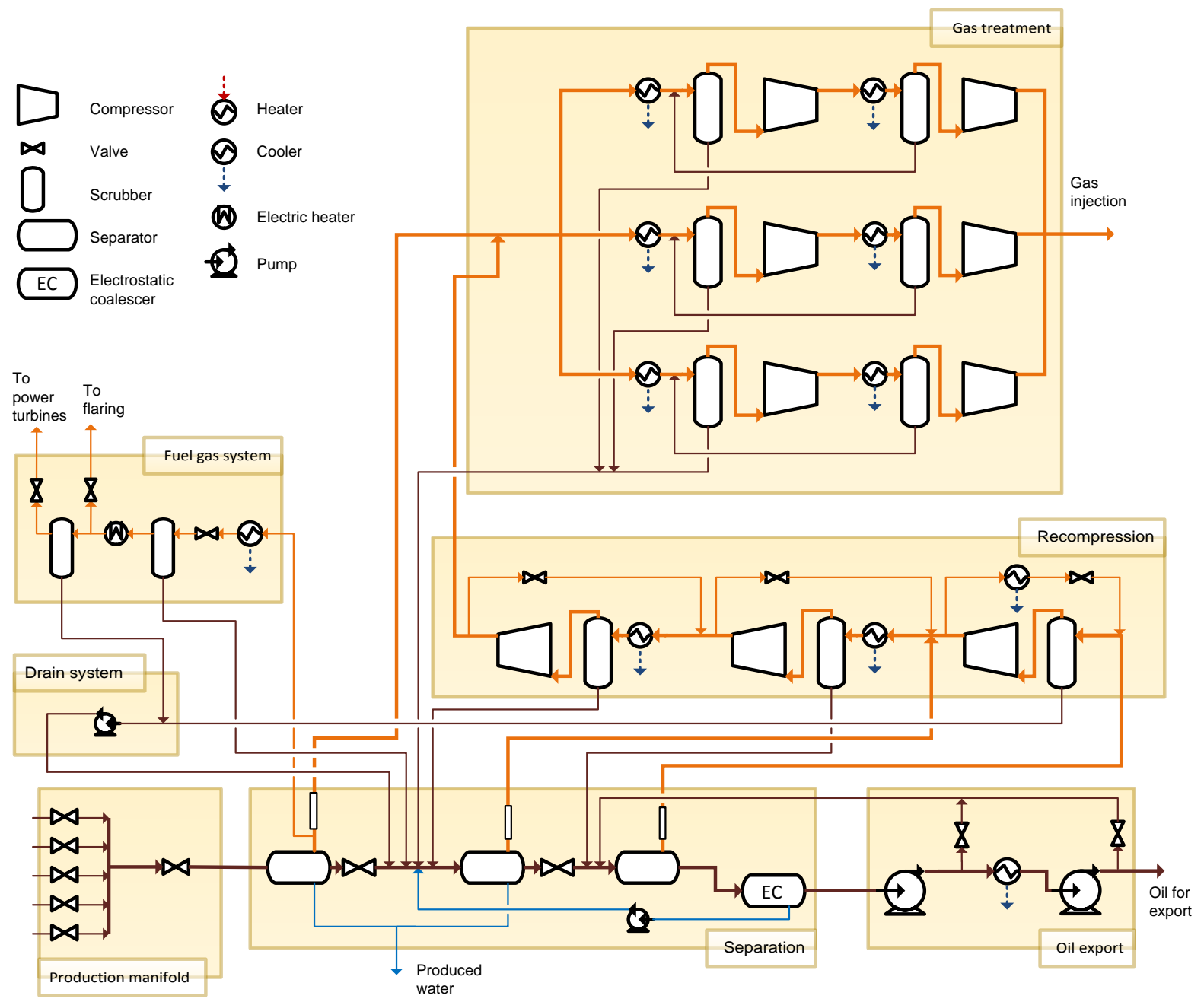

Figure A.11: Process flow diagram of the processing plant of Platform A. Gas streams are shown with orange arrows, water streams with blue arrows, and oil, condensate and mixed streams are shown with brown arrows.

\section{Platform B}

The process at Platform B was simulated for a real production day with stable and typical process conditions. The process flowsheet of Platform B is given in Fig. A.12.

Composition data was available for (i) the reservoir fluids at the start of the field lifetime and (ii) the export gas from a few months before the simulated production day. To simulate the well streams, the composition of the reservoir fluids was used, but to get the correct water-to-oil ratio, water was mixed in, while to get the correct gas-to-oil ratio, gas with the composition of the export gas was removed. The compositions of the three fluids used to simulate the well streams are given in Table A.9. Hypothetical components (developed by the oil company) were used to describe the heavy fractions of the reservoir fluids, 
Table A.8: Pressure, $p$, pressure drop, $\Delta P$, temperatures, $T$, and mass fractions, $x$, from the oil company's documentation of the cooling system set in the simulation of the cooling water system of Platform A.

\begin{tabular}{lcc}
\hline Process unit & Variable & Value \\
\hline Cooling medium to coolers & $p[\mathrm{bar}]$ & 7.8 \\
Pressure drop on cold side in coolers & $\Delta p[\mathrm{bar}]$ & 0.5 \\
Cooling medium to coolers & $T\left[{ }^{\circ} \mathrm{C}\right]$ & 17 \\
Cooling medium from all coolers mixed & $T\left[{ }^{\circ} \mathrm{C}\right]$ & 37.7 \\
Cooling medium, TEG weight fraction & $x_{T E G}[-]$ & 0.3 \\
Cooling medium, water weight fraction & $x_{\text {water }}[-]$ & 0.7 \\
Seawater to export cooler & $T\left[{ }^{\circ} \mathrm{C}\right]$ & 8.0 \\
\hline
\end{tabular}

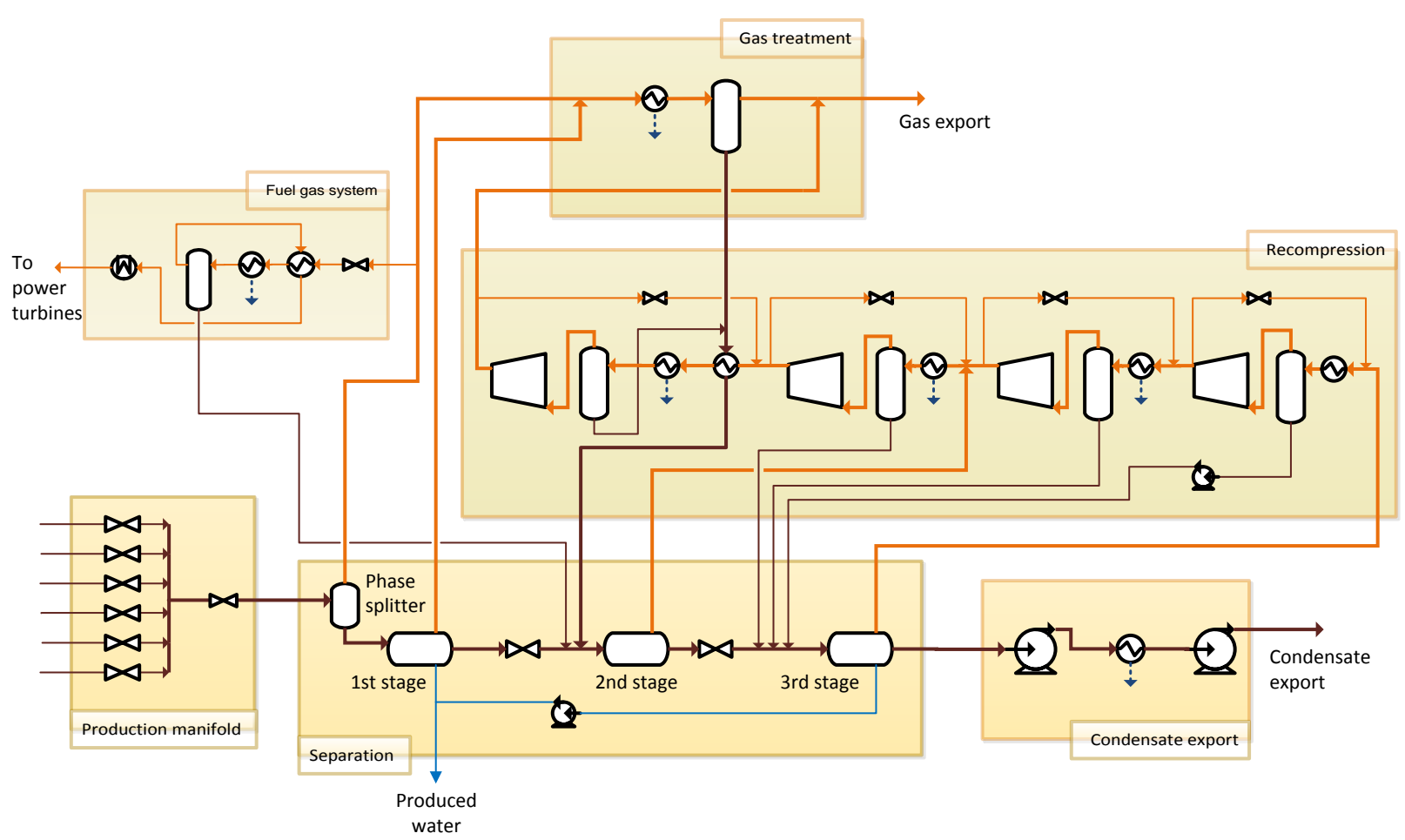

Figure A.12: Process flow diagram of the processing plant of Platform B. Gas streams are shown with orange arrows, water streams with blue arrows, and oil, condensate and mixed streams are shown with brown arrows. Symbol explanations can be found in Fig. A.11

and the properties set for these hypothetical components are given in Table A.10. Calculated flow rates of the gas, condensate and water phases in each well stream are given in Table A.11. Calculated flow rates are flow rates for each phase in the three-phase well streams estimated by the oil company. Measured flow rates of exported gas, exported condensate and produced water are given in Table A.12. The well stream flow rates of each phase were set such that the flow rates of the simulated product streams of the process fitted with the measured product streams in Table A.12 after all other input data in the simulation was set. The more uncertain calculated flow rates of the well streams in Table A.11 were used to set the ratio of flow from the different wells for each of the phases. 
Table A.9: Composition of fluids used for simulation of feed streams of Platform B. The composition of gas is a measured composition of the exported gas a few months before the simulated production day. The composition of reservoir fluids is the composition of the reservoir at start the start of the field lifetime.

\begin{tabular}{lccc}
\hline Component & Gas & Reservoir fluids & Water \\
\hline Nitrogen & $1.89 \cdot 10^{-3}$ & $1.80 \cdot 10^{-3}$ & 0 \\
CO $_{2}$ & $3.78 \cdot 10^{-2}$ & $3.53 \cdot 10^{-2}$ & 0 \\
Water & 0 & 0 & 1 \\
Methane & 0.831 & 0.801 & 0 \\
Ethane & $6.98 \cdot 10^{-2}$ & $7.00 \cdot 10^{-2}$ & 0 \\
Propane & $3.02 \cdot 10^{-2}$ & $3.09 \cdot 10^{-2}$ & 0 \\
i-Butane & $4.56 \cdot 10^{-3}$ & $4.80 \cdot 10^{-3}$ & 0 \\
n-Butane & $9.04 \cdot 10^{-3}$ & $1.01 \cdot 10^{-2}$ & 0 \\
i-Pentane & $2.71 \cdot 10^{-3}$ & $3.50 \cdot 10^{-3}$ & 0 \\
n-Pentane & $2.91 \cdot 10^{-3}$ & $4.00 \cdot 10^{-3}$ & 0 \\
HypoB-1 & $1.03 \cdot 10^{-2}$ & $5.10 \cdot 10^{-3}$ & 0 \\
HypoB-2 & 0 & $7.90 \cdot 10^{-3}$ & 0 \\
HypoB-3 & 0 & $8.50 \cdot 10^{-3}$ & 0 \\
HypoB-4 & 0 & $4.90 \cdot 10^{-3}$ & 0 \\
HypoB-5 & 0 & $4.50 \cdot 10^{-3}$ & 0 \\
HypoB-6 & 0 & $3.10 \cdot 10^{-3}$ & 0 \\
HypoB-7 & 0 & $2.00 \cdot 10^{-3}$ & 0 \\
HypoB-8 & 0 & $1.20 \cdot 10^{-3}$ & 0 \\
HypoB-9 & 0 & $8.00 \cdot 10^{-4}$ & 0 \\
HypoB-10 & 0 & $6.00 \cdot 10^{-4}$ & 0 \\
HypoB-11 & 0 & $3.00 \cdot 10^{-4}$ & 0 \\
HypoB-12 & 0 & $1.00 \cdot 10^{-4}$ & 0 \\
\hline & & &
\end{tabular}

Table A.10: Molecular weight, $M$, normal boiling point, $T_{b}$, ideal liquid density, $\rho_{(\text {id.liq. })}$, critical temperature, $T_{c}$, critical pressure, $p_{c}$, critical volume, $V_{c}$, and acentric factor, $\omega$, for the hypothetical components used to describe the heavy oil fractions of Platform B.

\begin{tabular}{cccccccc}
\hline & $M[\mathrm{~g} / \mathrm{mol}]$ & $T_{b}\left[{ }^{\circ} \mathrm{C}\right]$ & $\rho_{i d, l i q}\left[\mathrm{~kg} / \mathrm{m}^{3}\right]$ & $T_{c}\left[{ }^{\circ} \mathrm{C}\right]$ & $p_{c}[\mathrm{bar}]$ & $V_{c}\left[\mathrm{~m}^{3} / \mathrm{kmol}^{2}\right.$ & $\omega[-]$ \\
\hline HypoB-1 & 85.65 & 68.75 & 664.5 & 234.2 & 29.69 & 0.37 & 0.296 \\
HypoB-2 & 91.13 & 91.95 & 741 & 255 & 34.49 & 0.3938 & 0.454 \\
HypoB-3 & 104.3 & 116.7 & 765.5 & 279.3 & 30.35 & 0.4153 & 0.492 \\
HypoB-4 & 118.9 & 142.2 & 778 & 302.2 & 26.38 & 0.4571 & 0.534 \\
HypoB-5 & 140.1 & 176.3 & 790.7 & 331.6 & 22.35 & 0.5269 & 0.594 \\
HypoB-6 & 167.5 & 217.6 & 805.5 & 365.2 & 19.12 & 0.6203 & 0.669 \\
HypoB-7 & 197.5 & 255.9 & 818 & 397.8 & 16.87 & 0.7285 & 0.747 \\
HypoB-8 & 229 & 291.1 & 828.9 & 429 & 15.3 & 0.8467 & 0.825 \\
HypoB-9 & 256.6 & 318.6 & 838.6 & 454.5 & 14.38 & 0.952 & 0.89 \\
HypoB-10 & 289 & 349.8 & 849.1 & 483 & 13.61 & 1.081 & 0.963 \\
HypoB-11 & 336 & 390.1 & 861.8 & 521.5 & 12.81 & 1.271 & 1.059 \\
HypoB-12 & 403.6 & 439 & 876.9 & 573.2 & 12.09 & 1.555 & 1.177 \\
\hline
\end{tabular}


Table A.11: Calculated flow rates of the gas, oil and water phases in each well stream entering the production manifold at Platform B. These flow rates are estimated by the oil company, based on measurements, and they have a high uncertainty.

\begin{tabular}{lccc}
\hline Well & Gas $\left[10^{3} \mathrm{Sm}^{3} / \mathrm{h}\right]$ & Condensate $\left[\mathrm{Sm}^{3} / \mathrm{h}\right]$ & Water $\left[\mathrm{Sm}^{3} / \mathrm{h}\right]$ \\
\hline 5 & 153.9 & 73.61 & 1.72 \\
6 & 88 & 41.9 & 0.76 \\
11 & 136 & 65.1 & 1.53 \\
12 & 10.6 & 5.09 & 0.11 \\
13 & 42.1 & 22.64 & 0.37 \\
14 & 180.3 & 85.94 & 1.85 \\
\hline
\end{tabular}

Measured temperatures, pressures and flow rates set within the process are given in Table A.13, while values set based on assumptions and information from documentation of the equipment are given in Table A.14. The following simplifications were done in the simulation:

- In the real process there is an additional test separator in the 1st separation stage. This separator was merged into the main 1st stage separator.

- All identical parallel coolers, pumps and scrubbers were merged into one.

- The individual delivery and return temperatures of the cooling medium from each of the coolers was set to the measured delivery temperature and the temperature of the mixed cooling medium from all coolers (Table A.13), unless this gave a temperature difference betweem inlet gas and outlet cooling medium lower than $10{ }^{\circ} \mathrm{C}$. In the latter case the temperature was set to give a difference of $10{ }^{\circ} \mathrm{C}$.

- The gas fraction in the oil from the phase splitter was modified by splitting a part of the gas outlet stream and adding it to the oil stream.

- Pressure drops in tubes and separators and heat losses from tubes were neglected. Pressure drops in heat exchangers, where this was not a function of measured pressures (Table A.13) were set to 1.0 bar.

Measured process variables are compared with simulated process variables in Table A.15. The following points can be noted:

- The simulated temperature of the 1 st stage separator is within the uncertainty of $1^{\circ} \mathrm{C}$ (Table 6 ) of the measured value, while the simulated temperatures of the 2nd and 3rd stage separators deviated with 7.5 and $5.1^{\circ} \mathrm{C}$ from the measured temperatures. These temperatures are strongly dependent on the amount of condensate from the wet gas scrubber, and given that the temperature measurements are correct, the reason for the deviation is assumed to be too high condensate flow from the wet gas scrubber, which indicate that the feed composition is not correct. Decreasing the flow rate of condensate with $2 / 5$ gives the measured temperatures in the separators. Decreasing the liquid flow rate at the outlet of the wet gas cooler with $2 / 5$ gave less than $1 \%$ change in the exergy destruction in this unit, while changing the temperatures in the separators to the measured ones, resulted in increased exergy destruction in the coolers in the recompression train with $20 \%$ and decreased exergy destruction the compressors in the recompression train with 3.6\%. Other changes were less than $1 \%$.

- All simulated flow rates were within the uncertainty of $10 \%$ (Table 6) of the measured values.

- Simulated pressure of water and oil entering the water and 1st oil pumps, are 2.4 bar, while the measured values are 3.75 and 3.86 bar, respectively. These deviations are found because height differences are not taken into consideration in the simulation. As discussed for Platform A [9], this has little impact on the overall results. 
Table A.12: Measured flow rates in process steams leaving Platform B.

\begin{tabular}{lll}
\hline Produced fluid & Variable & Value \\
\hline Exported condensate & $F\left[\mathrm{Sm}^{3} / \mathrm{h}\right]$ & 238.9 \\
Exported gas & $F\left[10^{3} \mathrm{Sm}^{3} / \mathrm{h}\right]$ & 761 \\
Produced water & $F\left[\mathrm{~m}^{3} / \mathrm{h}\right]$ & 12.6 \\
\hline
\end{tabular}

Table A.13: Measured process variables set in the simulated process flowsheet of Platform B.

\begin{tabular}{|c|c|c|c|c|c|}
\hline Process stream description & Variable & Value & Process stream description & Variable & Value \\
\hline Production manifold & & & Recompression & & \\
\hline From well 5 , valve, in & $p[\mathrm{bar}]$ & 131.2 & 1st stage compressor, in & $p[\mathrm{bar}]$ & 2.26 \\
\hline From well 6 , valve, in & $p$ [bar] & 155.2 & 1st stage compressor, out & $p$ [bar] & 9.35 \\
\hline From well 11, valve, in & $p[\mathrm{bar}]$ & 127.4 & 2nd stage compressor, in & $p$ [bar] & 8.90 \\
\hline From well 12 , valve, in & $p$ [bar] & 123.2 & 2nd stage compressor, out & $p$ [bar] & 27.88 \\
\hline From well 13 , valve, in & $p$ [bar] & 124.4 & 3rd stage compressor, in & $p$ [bar] & 27.15 \\
\hline From well 14 , valve, in & $p$ [bar] & 145.9 & 3rd stage compressor, out & $p$ [bar] & 62.87 \\
\hline From well 5 , valve, out & $p$ [bar] & 122 & 4th stage compressor, in & $p$ [bar] & 61.87 \\
\hline From well 6 , valve, out & $p$ [bar] & 121.3 & 4th stage compressor, out & $p$ [bar] & 118.4 \\
\hline From well 11, valve, out & $p$ [bar] & 122.4 & Condensate pump, out & $p$ [bar] & 5.7 \\
\hline From well 12 , valve, out & $p$ [bar] & 121.1 & 1st stage cooler, out & $T\left[{ }^{\circ} \mathrm{C}\right]$ & 29.4 \\
\hline From well 13, valve, out & $p$ [bar] & 121.7 & 1st stage compressor, out & $T\left[{ }^{\circ} \mathrm{C}\right]$ & 101.3 \\
\hline From well 14, valve, out & $p$ [bar] & 121.6 & 2nd stage cooler, out & $T\left[{ }^{\circ} \mathrm{C}\right]$ & 31.6 \\
\hline From well 5, valve, in & $T\left[{ }^{\circ} \mathrm{C}\right]$ & 109.6 & 2nd stage compressor, out & $T\left[{ }^{\circ} \mathrm{C}\right]$ & 115.1 \\
\hline From well 6 , valve, in & $T\left[{ }^{\circ} \mathrm{C}\right]$ & 107 & 3rd stage cooler, out & $T\left[{ }^{\circ} \mathrm{C}\right]$ & $30.0^{a}$ \\
\hline From well 11, valve, in & $T\left[{ }^{\circ} \mathrm{C}\right]$ & 110.1 & 3rd stage compressor, out & $T\left[{ }^{\circ} \mathrm{C}\right]$ & 95.5 \\
\hline From well 12 , valve, in & $T\left[{ }^{\circ} \mathrm{C}\right]$ & 63.9 & 4th stage cooler, out & $T\left[{ }^{\circ} \mathrm{C}\right]$ & $35.0^{a}$ \\
\hline From well 13 , valve, in & $T\left[{ }^{\circ} \mathrm{C}\right]$ & 101 & 4th stage compressor, out & $T\left[{ }^{\circ} \mathrm{C}\right]$ & 88.4 \\
\hline From well 14 , valve, in & $T\left[{ }^{\circ} \mathrm{C}\right]$ & 110.5 & 1st stage compressor, in & $F\left[\mathrm{~m}^{3} / \mathrm{h}\right]$ & 7200 \\
\hline Separation & & & 2nd stage compressor, in & $F\left[\mathrm{~m}^{3} / \mathrm{h}\right]$ & 1200 \\
\hline 1st stage separator & $p$ [bar] & 119.6 & 3rd stage compressor, in & $F\left[\mathrm{~m}^{3} / \mathrm{h}\right]$ & 1410 \\
\hline 2nd stage separator & $p$ [bar] & 27.8 & 4th stage compressor, in & $F\left[\mathrm{~m}^{3} / \mathrm{h}\right]$ & 650 \\
\hline 3rd stage separator & $p$ [bar] & 2.4 & Flare system & & \\
\hline Phase splitter, gas out & $F\left[\mathrm{Sm}^{3} / \mathrm{h}\right]$ & 74,000 & To flare & $F\left[\mathrm{~m}^{3} / \mathrm{h}\right]$ & 94.3 \\
\hline Water pump, out & $p[\mathrm{bar}]$ & 61.06 & Condensate export & & \\
\hline Fuel gas system & & & 2nd pump, in & $p[\mathrm{bar}]$ & 18.78 \\
\hline After inlet valve & $p[\mathrm{bar}]$ & 39 & 2nd pump, out & $p$ [bar] & 106.7 \\
\hline Fuel gas cooler, out & $T\left[{ }^{\circ} \mathrm{C}\right]$ & 29.8 & Condensate cooler, out & $T\left[{ }^{\circ} \mathrm{C}\right]$ & 49.4 \\
\hline Fuel gas heater, out & $T\left[{ }^{\circ} \mathrm{C}\right]$ & 49.8 & 2nd pump, out & $T\left[{ }^{\circ} \mathrm{C}\right]$ & 56.4 \\
\hline To power turbines & $F\left[\mathrm{Sm}^{3} / \mathrm{h}\right]$ & 2300 & Cooling system & & \\
\hline Gas treatment & & & Cooling medium, delivery & $p[\mathrm{bar}]$ & 12.9 \\
\hline Wet gas scrubber & $p[\mathrm{bar}]$ & 118.2 & Cooling medium, delivery & $T\left[{ }^{\circ} \mathrm{C}\right]$ & 24.5 \\
\hline Wet gas cooler, out & $T\left[{ }^{\circ} \mathrm{C}\right]$ & 32 & Cooling medium from all coolers mixed & $T\left[{ }^{\circ} \mathrm{C}\right]$ & 55 \\
\hline
\end{tabular}

${ }^{a}$ Set point for cooler.

Table A.14: Values for efficiency, $\eta$, overall heat transfer coefficient, $U$, heat transfer surface area, $A$, temperature, $T$, Pressure, $p$, mass fraction, $x$, and electric work, $\mathrm{W}_{e l}$, assumed or from documentation from process equipment for Platform B.

\begin{tabular}{llll}
\hline Process unit & Variable & Value & Source \\
\hline $\begin{array}{l}\text { Separation } \\
\text { Water pump }\end{array}$ & $\eta[\%]$ & 75 & Assumed \\
$\begin{array}{l}\text { Recompression } \\
\text { Cross heat exchanger }\end{array}$ & Overall $U A\left[\mathrm{~kJ} /{ }^{\circ} \mathrm{C}-\mathrm{h}\right]$ & 580,000 & Assumed, operators \\
$\begin{array}{l}\text { Condensate export } \\
\text { 1st pump }\end{array}$ & $\eta[\%]$ & 55 & Pump performance curves \\
$\begin{array}{l}\text { Cooling system } \\
\text { Cooling medium, MEG weight fraction } \\
\text { Cooling medium, water weight fraction }\end{array}$ & $x_{M E G}[-]$ & 0.35 & Documentation of cooling system \\
$\begin{array}{l}\text { Fuel gas system } \\
\text { Fuel gas heater }\end{array}$ & $x_{\text {water }}[-]$ & 0.65 & Documentation of cooling system \\
\hline
\end{tabular}


Table A.15: Measured values for temperature, $T$, Pressure, $p$, and flow, $F$, compared with simulated values for Platform B.

\begin{tabular}{lccc}
\hline Process stream description & Variable & Measured value & Simulated value \\
\hline Separation & & & \\
1st stage separator & $T\left[{ }^{\circ} \mathrm{C}\right]$ & 105.5 & 105.8 \\
2nd stage separator & $T\left[{ }^{\circ} \mathrm{C}\right]$ & 86.9 & 79.4 \\
3rd stage separator & $T\left[{ }^{\circ} \mathrm{C}\right]$ & 67.3 & 62.2 \\
1st stage separator, water out & $F\left[\mathrm{~m}^{3} / \mathrm{h}\right]$ & 4.8 & 4.3 \\
3rd stage separator, water out & $F\left[\mathrm{~m}^{3} / \mathrm{h}\right]$ & 7.8 & 8.3 \\
Water pump, in & $p[\mathrm{bar}]$ & 3.75 & 2.4 \\
Gas treatment & & & \\
Wet gas scrubber, out & $F\left[10^{3} \mathrm{Sm}^{3} / \mathrm{h}\right]$ & 690 & 720 \\
Condensate export & & & \\
1st pump, in & $p[\mathrm{bar}]$ & 3.86 & 2.4 \\
1st pump, out & $F\left[\mathrm{~m}^{3} / \mathrm{h}\right]$ & 250 & 250 \\
2nd pump, out & $F\left[\mathrm{~m}^{3} / \mathrm{h}\right]$ & 250 & 250 \\
\hline
\end{tabular}




\section{Platform $C$}

The process at Platform $\mathrm{C}$ was simulated for a real production day with stable conditions, and the measured data given for this process is measured at 12.00 for this day. The day was a typical day with the exception that the produced water injection system was not in operation, so the water was discharged to the sea. The process flowsheet of Platform C is given in Fig. A.13.

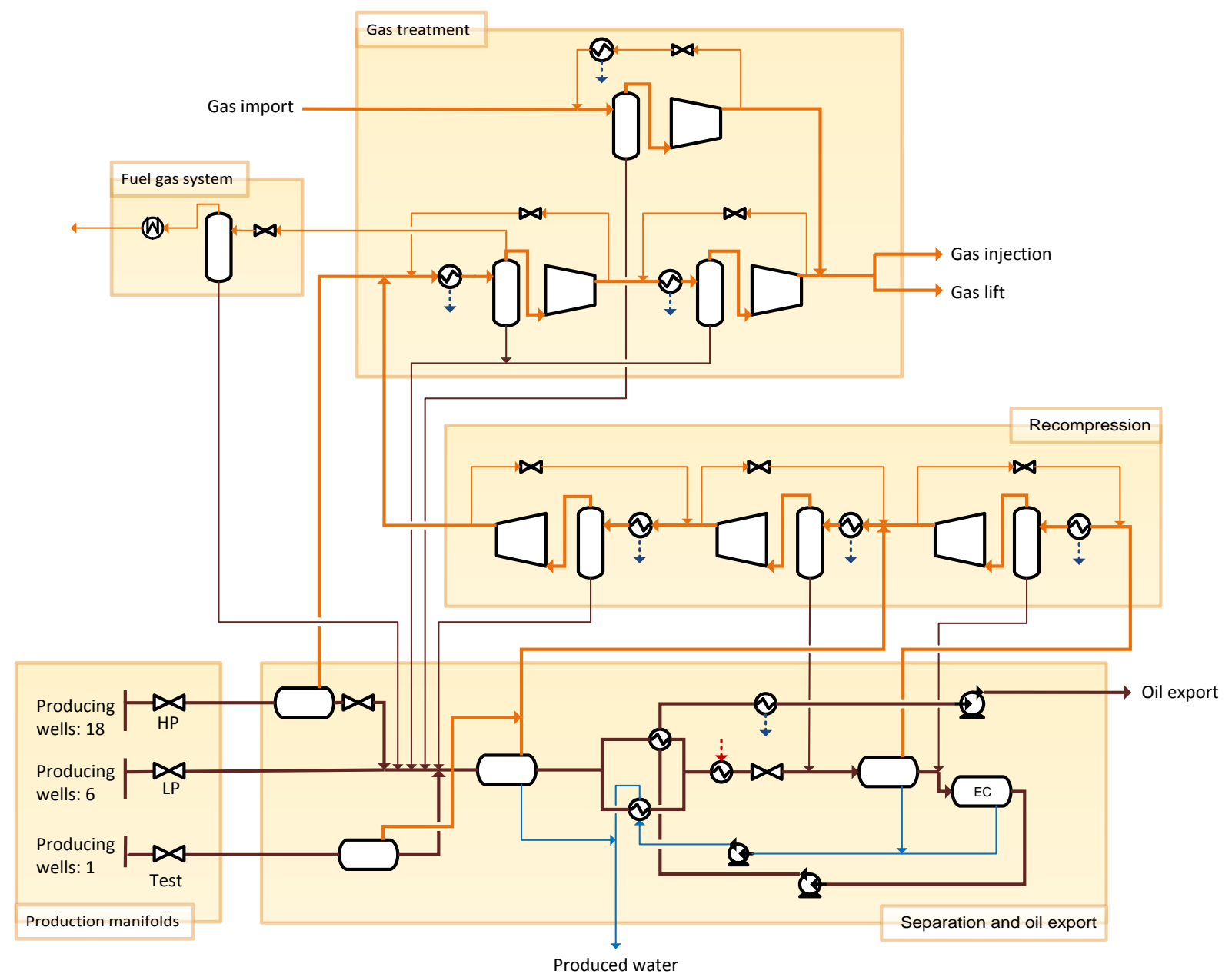

Figure A.13: Process flow diagram of the processing plant of Platform C. Gas streams are shown with orange arrows, water streams with blue arrows, and oil, condensate and mixed streams are shown with brown arrows. Symbol explanations can be found in Fig. A.11.

Composition data was available for (i) the reservoir fluids at the start of the field lifetime and (ii) typical composition of the imported gas (which is injected into the reservoir for pressure maintenance). These two fluids plus water was mixed to produce well streams giving realistic water-to-oil and gas-to-oil ratios. The compositions of these three fluids are given in Table A.16. Properties of hypothetical components (developed by the oil company) used to describe the heavy fractions are given in Table A.17. Calculated flow rates for each well stream are given in Table A.18. Calculated flow rates are flow rates for each phase in the three-phase well streams estimated by the oil company. Measured flow rates for product streams are given in Table A.19. The oil and gas flow rates in each well were set to make the simulated product streams fit with the measured product streams (Table A.19) after all other input data in the simulation was set. The more uncertain calculated flow rates in the well streams (Table A.18) were used to set the ratio of gas flow 
rates from each well and the ratio of oil flow rate from each well. Since the produced water was discharged to the sea, and not injected as usual, the flow rate of the produced water was not measured. The water flow rates in each well was therefore set equal to the calculated flow rate (Table A.18).

Table A.16: Composition of fluids (molar fraction) used for simulation of feed streams of Platform C. The composition of 'gas' is the typical composition of the imported gas. The composition of 'reservoir fluids' is the composition of the reservoir at start the start of the field lifetime.

\begin{tabular}{lccc}
\hline Component & Gas & Reservoir fluids & Water \\
\hline Nitrogen & $8.2 \cdot 10^{-3}$ & $2.7 \cdot 10^{-3}$ & 0 \\
$\mathrm{CO}_{2}$ & $1.4 \cdot 10^{-2}$ & $6.0 \cdot 10^{-4}$ & 0 \\
Water & $1.0 \cdot 10^{-6}$ & 0 & 1 \\
Methane & $8.6 \cdot 10^{-1}$ & $1.6 \cdot 10^{-1}$ & 0 \\
Ethane & $7.8 \cdot 10^{-2}$ & $1.1 \cdot 10^{-2}$ & 0 \\
Propane & $3.1 \cdot 10^{-2}$ & $2.8 \cdot 10^{-3}$ & 0 \\
i-Butane & $2.6 \cdot 10^{-3}$ & $5.8 \cdot 10^{-3}$ & 0 \\
n-Butane & $4.0 \cdot 10^{-3}$ & $1.6 \cdot 10^{-3}$ & 0 \\
i-Pentane & $4.7 \cdot 10^{-4}$ & $3.7 \cdot 10^{-3}$ & 0 \\
n-Pentane & $4.3 \cdot 10^{-4}$ & $1.0 \cdot 10^{-3}$ & 0 \\
HypoA-1 & $2.4 \cdot 10^{-4}$ & 0 & 0 \\
HypoC-1 & 0 & $5.5 \cdot 10^{-2}$ & 0 \\
HypoC-2 & 0 & $8.3 \cdot 10^{-2}$ & 0 \\
HypoC-3 & 0 & $1.4 \cdot 10^{-1}$ & 0 \\
HypoC-4 & 0 & $2.4 \cdot 10^{-1}$ & 0 \\
HypoC-5 & 0 & $2.0 \cdot 10^{-1}$ & 0 \\
HypoC-6 & 0 & $9.5 \cdot 10^{-2}$ & 0 \\
\hline
\end{tabular}

Table A.17: Molecular weight, $M$, normal boiling point, $T_{b}$, ideal liquid density, $\rho_{(i d . l i q .)}$, critical temperature, $T_{c}$, and critical pressure, $p_{c}$, for the hypothetical components used to describe the heavy oil fractions of Platform C.

\begin{tabular}{cccccc}
\hline & $M[\mathrm{~g} / \mathrm{mol}]$ & $T_{b}\left[{ }^{\circ} \mathrm{C}\right]$ & $\rho_{\text {id.liq. }}\left[\mathrm{kg} / \mathrm{m}^{3}\right]$ & $T_{c}\left[{ }^{\circ} \mathrm{C}\right]$ & $p_{c}[\mathrm{bar}]$ \\
\hline HypoA-1 & 81.00 & 73.00 & 721.2 & 247.9 & 33.46 \\
HypoC-1 & 98.78 & 85.76 & 754.3 & 269.3 & 35.50 \\
HypoC-2 & 141.2 & 173.9 & 816.6 & 365.7 & 27.19 \\
HypoC-3 & 185.8 & 240.5 & 861.0 & 434.1 & 22.71 \\
HypoC-4 & 241.1 & 314.5 & 902.5 & 505.2 & 18.54 \\
HypoC-5 & 404.5 & 487.1 & 955.3 & 647.0 & 10.45 \\
HypoC-6 & 907.0 & 552.8 & 1007 & 710.0 & 9.610 \\
\hline
\end{tabular}


Table A.18: Calculated flow rates of the gas, oil and water phases for each well stream entering the production manifolds at Platform C.

\begin{tabular}{|c|c|c|c|}
\hline Well & $\begin{array}{c}\text { Gas } \\
{\left[10^{3} \mathrm{Sm}^{3} / \mathrm{h}\right]}\end{array}$ & $\begin{array}{c}\text { Oil } \\
{\left[\mathrm{Sm}^{3} / \mathrm{h}\right]}\end{array}$ & $\begin{array}{c}\text { Water } \\
{\left[\mathrm{Sm}^{3} / \mathrm{h}\right]}\end{array}$ \\
\hline \multicolumn{4}{|c|}{ High pressure production manifold } \\
\hline 2 & 18.06 & 43.69 & 9.59 \\
\hline 6 & 6.84 & 17.49 & 4.10 \\
\hline 8 & 7.29 & 17.56 & 0.54 \\
\hline 9 & 3.97 & 11.49 & 0.01 \\
\hline 10 & 7.35 & 20.03 & 0.83 \\
\hline 15 & 30.52 & 133.09 & 18.15 \\
\hline 16 & 30.51 & 106.90 & 5.63 \\
\hline 17 & 3.88 & 7.41 & 0.01 \\
\hline 18 & 6.85 & 13.49 & 0.01 \\
\hline 19 & 7.22 & 33.02 & 0.33 \\
\hline 21 & 2.72 & 7.81 & 0.00 \\
\hline 25 & 4.43 & 22.91 & 3.42 \\
\hline 26 & 6.59 & 20.60 & 0.42 \\
\hline 27 & 3.71 & 14.40 & 0.45 \\
\hline 28 & 15.51 & 41.93 & 2.21 \\
\hline 30 & 6.15 & 19.17 & 4.21 \\
\hline 35 & 18.62 & 48.19 & 3.08 \\
\hline 40 & 6.40 & 27.01 & 1.42 \\
\hline \multicolumn{4}{|c|}{ Low pressure production manifold } \\
\hline 3 & 2.88 & 183.26 & 29.83 \\
\hline 12 & 9.14 & 24.28 & 2.40 \\
\hline 13 & 1.65 & 105.37 & 89.76 \\
\hline 22 & 0.39 & 14.28 & 0.60 \\
\hline 34 & 0.21 & 14.15 & 0.44 \\
\hline 39 & 0.68 & 43.17 & 54.94 \\
\hline \multicolumn{4}{|c|}{ Test manifold } \\
\hline 1 & 22.08 & 91.81 & 27.42 \\
\hline
\end{tabular}

Table A.19: Measured flow rates in process steams leaving Platform C with uncertainty at $95 \%$ confidence level.

\begin{tabular}{lcc}
\hline Produced fluid & Variable & Value \\
\hline Oil & $F\left[\mathrm{~m}^{3} / \mathrm{h}\right]$ & $1147 \pm 3$ \\
Injected gas & $F\left[10^{3} \mathrm{Sm}^{3} / \mathrm{h}\right]$ & $360 \pm 40$ \\
Gas lift & $F\left[10^{3} \mathrm{Sm}^{3} / \mathrm{h}\right]$ & $22 \pm 2$ \\
\hline
\end{tabular}


Measured temperatures, pressures and flow rates set in the simulation are given in Table A.20, while values set based on assumptions and information from documentation of the equipment are given in Table A.21. The following simplifications were done in the simulation:

- All identical parallel coolers, pumps and scrubbers were merged into one.

- The delivery and return temperatures of the cooling medium in each of the coolers were set to the values for delivery and return temperature given in the documentation of the seawater system (Table A.21).

- Pressure drops and heat losses in tubes and separators were neglected.

- For heat exchangers where values for pressure drops were not direct functions of measured pressures (Table A.20), pressure drops were set equal to values found in datasheets (Table A.21) or to 1.0 bar.

- A dummy pump was included to increase the pressure of the condensate from 1st scrubber in the recompression train, to avoid inconsistencies in the flowsheet. The pressure out of the pump was set to the pressure out from the 2 nd stage separator. In reality the pressure is increased due to height differences.

Simulated values are compared with measured values in Table A.22. The following points can be noted:

- Most simulated temperatures (21 out of 28 ) are within the uncertainty of $1^{\circ} \mathrm{C}$ (Table 6 ) of the measured temperatures. The maximum deviation between measured and simulated temperature is $3.7^{\circ} \mathrm{C}$, and this is either due to measurements with higher errors than the assumed uncertainty, or due to inaccuracies in the equation of state. Since deviations higher than $1{ }^{\circ} \mathrm{C}$ only take place in a few of the wells, the effect of this is assumed to be negligible compared to the error sources mentioned in Section 4 .

- Simulated pressure of water and oil entering the water and 1st oil pumps, are 2.75 bar, while the measured values are 4.20 and 3.96 bar, respectively. These deviations are found because height differences are not taken into consideration in the simulation. As discussed for Platform A [9], this has little impact on the overall results.

- Simulated flow rates in the oil export and gas treatment sections are within an uncertainty of the measured values of $10 \%$ (Table 6 ). 
Table A.20: Measured process variables set in the simulated process flowsheet of Platform C.

\begin{tabular}{|c|c|c|c|c|c|}
\hline Process stream description & Variable & Value & Process stream description & Variable & Value \\
\hline \multicolumn{3}{|c|}{ High pressure production manifold } & \multicolumn{3}{|c|}{ Low pressure production manifold } \\
\hline From well 2 , valve, in & $p[\mathrm{bar}]$ & 85.8 & From well 3 , valve, in & $p$ [bar] & 14.61 \\
\hline From well 6 , valve, in & $p$ [bar] & 95.9 & From well 12 , valve, in & $p$ [bar] & 90.2 \\
\hline From well 8 , valve, in & $p$ [bar] & 93.9 & From well 13 , valve, in & $p$ [bar] & 13.04 \\
\hline From well 9 , valve, in & $p$ [bar] & 92.1 & From well 22 , valve, in & $p$ [bar] & 70.2 \\
\hline From well 10 , valve, in & $p$ [bar] & 95.6 & From well 34 , valve, in & $p$ [bar] & 48.4 \\
\hline From well 15 , valve, in & $p$ [bar] & 65.4 & From well 39 , valve, in & $p$ [bar] & 22.5 \\
\hline From well 16 , valve, in & $p$ [bar] & 77.0 & From well 3 , valve, out & $p$ [bar] & 9.20 \\
\hline From well 17 , valve, in & $p$ [bar] & 110.5 & From well 12 , valve, out & $p$ [bar] & 8.08 \\
\hline From well 18 , valve, in & $p$ [bar] & 105.4 & From well 13 , valve, out & $p$ [bar] & 9.36 \\
\hline From well 19 , valve, in & $p$ [bar] & 83.7 & From well 22 , valve, out & $p$ [bar] & 7.85 \\
\hline From well 21 , valve, in & $p$ [bar] & 96.5 & From well 34 , valve, out & $p$ [bar] & 8.05 \\
\hline From well 25 , valve, in & $p$ [bar] & 87.4 & From well 39 , valve, out & $p$ [bar] & 8.22 \\
\hline From well 26 , valve, in & $p$ [bar] & 94.1 & From well 3 , valve, in & $T\left[{ }^{\circ} \mathrm{C}\right]$ & 71.1 \\
\hline From well 27 , valve, in & $p$ [bar] & 80.8 & From well 12 , valve, in & $T\left[{ }^{\circ} \mathrm{C}\right]$ & 61.7 \\
\hline From well 28 , valve, in & $p$ [bar] & 94.5 & From well 13 , valve, in & $T\left[{ }^{\circ} \mathrm{C}\right]$ & 70.9 \\
\hline From well 30 , valve, in & $p$ [bar] & 94.0 & From well 22 , valve, in & $T\left[{ }^{\circ} \mathrm{C}\right]$ & 56.0 \\
\hline From well 35 , valve, in & $p$ [bar] & 96.6 & From well 34 , valve, in & $T\left[{ }^{\circ} \mathrm{C}\right]$ & 57.2 \\
\hline From well 40 , valve, in & $p$ [bar] & 88.5 & From well 39 , valve, in & $T\left[{ }^{\circ} \mathrm{C}\right]$ & 71.8 \\
\hline From well 2 , valve, out & $p$ [bar] & 47.1 & Test manifold & & \\
\hline From well 6 , valve, out & $p$ [bar] & 47.0 & From well 1 , valve, in & $p$ [bar] & 60.4 \\
\hline From well 8 , valve, out & $p$ [bar] & 47.0 & From well 1 , valve, out & $p$ [bar] & 14.76 \\
\hline From well 9, valve, out & $p$ [bar] & 47.0 & From well 1 , valve, in & $T\left[{ }^{\circ} \mathrm{C}\right]$ & 68.4 \\
\hline From well 10, valve, out & $p$ [bar] & 47.1 & Recompression & & \\
\hline From well 15 , valve, out & $p$ [bar] & 47.8 & 1 st compressor, in & $p$ [bar] & 1.24 \\
\hline From well 16 , valve, out & $p$ [bar] & 47.4 & 1st compressor, out & $p$ [bar] & 7.14 \\
\hline From well 17 , valve, out & $p$ [bar] & 47.2 & 2nd compressor, in & $p$ [bar] & 5.84 \\
\hline From well 18 , valve, out & $p$ [bar] & 47.0 & 2nd compressor, out & $p$ [bar] & 17.5 \\
\hline From well 19 , valve, out & $p$ [bar] & 46.9 & 3rd compressor, in & $p$ [bar] & 16.8 \\
\hline From well 21 , valve, out & $p$ [bar] & 46.9 & 3rd compressor, out & $p$ [bar] & 45.7 \\
\hline From well 25 , valve, out & $p$ [bar] & 46.9 & 1st cooler, out & $T\left[{ }^{\circ} \mathrm{C}\right]$ & 30.5 \\
\hline From well 26 , valve, out & $p$ [bar] & 46.9 & 1st compressor, out & $T\left[{ }^{\circ} \mathrm{C}\right]$ & 164.7 \\
\hline From well 27 , valve, out & $p$ [bar] & 46.8 & 2nd cooler, out & $T\left[{ }^{\circ} \mathrm{C}\right]$ & 28.3 \\
\hline From well 28 , valve, out & $p$ [bar] & 47.0 & 2nd compressor, out & $T\left[{ }^{\circ} \mathrm{C}\right]$ & 123.0 \\
\hline From well 30, valve, out & $p$ [bar] & 47.2 & 3rd cooler, out & $T\left[{ }^{\circ} \mathrm{C}\right]$ & 26.5 \\
\hline From well 35 , valve, out & $p$ [bar] & 47.1 & 3rd compressor, out & $T\left[{ }^{\circ} \mathrm{C}\right]$ & 125.1 \\
\hline From well 40, valve, out & $p$ [bar] & 47.0 & 1 st compressor, in & $F\left[10^{3} \mathrm{Sm}^{3} / \mathrm{h}\right]$ & 6.3 \\
\hline From well 2, valve, in & $T\left[{ }^{\circ} \mathrm{C}\right]$ & 64.5 & 2nd compressor, in & $F\left[10^{3} \mathrm{Sm}^{3} / \mathrm{h}\right]$ & 101 \\
\hline From well 6 , valve, in & $T\left[{ }^{\circ} \mathrm{C}\right]$ & 66.1 & 3rd compressor, in & $F\left[10^{3} \mathrm{Sm}^{3} / \mathrm{h}\right]$ & 87 \\
\hline From well 8 , valve, in & $T\left[{ }^{\circ} \mathrm{C}\right]$ & 58.0 & Gas treatment & & \\
\hline From well 9 , valve, in & $T\left[{ }^{\circ} \mathrm{C}\right]$ & 60.6 & 1st compressor, in & $p$ [bar] & 44.4 \\
\hline From well 10 , valve, in & $T\left[{ }^{\circ} \mathrm{C}\right]$ & 62.4 & 1st compressor, out & $p$ [bar] & 94.3 \\
\hline From well 15 , valve, in & $T\left[{ }^{\circ} \mathrm{C}\right]$ & 71.8 & 2nd compressor, in & $p$ [bar] & 93.1 \\
\hline From well 16 , valve, in & $T\left[{ }^{\circ} \mathrm{C}\right]$ & 66.8 & 2nd compressor, out & $p$ [bar] & 184.9 \\
\hline From well 17 , valve, in & $T\left[{ }^{\circ} \mathrm{C}\right]$ & 51.7 & Imported gas & $p$ [bar] & 110.2 \\
\hline From well 18 , valve, in & $T\left[{ }^{\circ} \mathrm{C}\right]$ & 57.9 & Import gas compressor, in & $p$ [bar] & 108.7 \\
\hline From well 19 , valve, in & $T\left[{ }^{\circ} \mathrm{C}\right]$ & 61.9 & Import gas compressor, out & $p$ [bar] & 184.3 \\
\hline From well 21 , valve, in & $T\left[{ }^{\circ} \mathrm{C}\right]$ & 50.5 & 1st cooler, out & $T\left[{ }^{\circ} \mathrm{C}\right]$ & 27.0 \\
\hline From well 25 , valve, in & $T\left[{ }^{\circ} \mathrm{C}\right]$ & 58.5 & 1st compressor, out & $T\left[{ }^{\circ} \mathrm{C}\right]$ & 91.9 \\
\hline From well 26 , valve, in & $T\left[{ }^{\circ} \mathrm{C}\right]$ & 60.9 & 2nd cooler, out & $T\left[{ }^{\circ} \mathrm{C}\right]$ & 30.0 \\
\hline From well 27 , valve, in & $T\left[{ }^{\circ} \mathrm{C}\right]$ & 57.0 & 2nd compressor, out & $T\left[{ }^{\circ} \mathrm{C}\right]$ & 91.6 \\
\hline From well 28 , valve, in & $T\left[{ }^{\circ} \mathrm{C}\right]$ & 60.9 & Imported gas & $T\left[{ }^{\circ} \mathrm{C}\right]$ & 4.4 \\
\hline From well 30 , valve, in & $T\left[{ }^{\circ} \mathrm{C}\right]$ & 64.2 & Import gas cooler, out & $T\left[{ }^{\circ} \mathrm{C}\right]$ & 29.0 \\
\hline From well 35 , valve, in & $T\left[{ }^{\circ} \mathrm{C}\right]$ & 67.8 & Import gas compressor, in & $T\left[{ }^{\circ} \mathrm{C}\right]$ & 9.0 \\
\hline From well 40 , valve, in & $T\left[{ }^{\circ} \mathrm{C}\right]$ & 64.4 & Import gas compressor, out & $T\left[{ }^{\circ} \mathrm{C}\right]$ & 52.5 \\
\hline Separation and oil export & & & Imported gas & $F\left[10^{3} \mathrm{Sm}^{3} / \mathrm{h}\right]$ & 159 \\
\hline HP degasser & $p$ [bar] & 46.0 & For gas lift, HP & $F\left[10^{3} \mathrm{Sm}^{3} / \mathrm{h}\right]$ & 0 \\
\hline Test separator & $p$ [bar] & 12.9 & For gas lift, LP & $F\left[10^{3} \mathrm{Sm}^{3} / \mathrm{h}\right]$ & 22 \\
\hline 1st stage separator & $p$ [bar] & 7.22 & For injection & $F\left[10^{3} \mathrm{Sm}^{3} / \mathrm{h}\right]$ & $360 \pm 40$ \\
\hline 2nd stage separator & $p$ [bar] & 2.75 & Fuel gas system & & \\
\hline Water pump, out & $p$ [bar] & 13.48 & Scrubber, in & $p$ [bar] & 39.0 \\
\hline 1st oil pump, out & $p$ [bar] & 12.48 & Heater, out & $T\left[{ }^{\circ} \mathrm{C}\right]$ & 60.9 \\
\hline 2nd oil pump, in & $p$ [bar] & 9.46 & To flare & $F\left[\mathrm{Sm}^{3} / \mathrm{h}\right]$ & 0 \\
\hline 2nd oil pump, out & $p$ [bar] & 99.1 & To turbines & $F\left[\mathrm{Sm}^{3} / \mathrm{h}\right]$ & $9650 \pm 170$ \\
\hline Oil heater, out & $T\left[{ }^{\circ} \mathrm{C}\right]$ & 98.0 & & & \\
\hline Export cooler, in & $T\left[{ }^{\circ} \mathrm{C}\right]$ & 80.8 & & & \\
\hline Export cooler, out & $T\left[{ }^{\circ} \mathrm{C}\right]$ & 74.0 & & & \\
\hline
\end{tabular}


Table A.21: Split flow ratios, values for overall heat transfer coefficient, $U$, heat transfer surface area, $A$, pressure drop, $\Delta p$, efficiency, $\eta$, mass fraction, $x$, pressure, $p$ and temperature, $T$, assumed or from documentation from process equipment for Platform C

\begin{tabular}{|c|c|c|c|}
\hline Process unit & Variable & Value & Source \\
\hline \multicolumn{4}{|l|}{ Separation and oil export } \\
\hline Split flow ratio, to oil-oil heat exchanger & {$[-]$} & 0.5 & Documentation of separation system \\
\hline Split flow ratio, to oil-water heat exchanger & {$[-]$} & 0.5 & Documentation of separation system \\
\hline Oil-water heat exchanger, UA & $U A[\mathrm{~kJ} / \mathrm{C}-\mathrm{h}]$ & $1.85 \cdot 10^{6}$ & Assumed, operators \\
\hline Electrostatic coalescer, water in oil & {$[\%]$} & 0.5 & Product specification \\
\hline Oil-oil heat exchanger, hot side & $\Delta p[\mathrm{bar}]$ & 1.5 & Datasheet \\
\hline Oil-oil heat exchanger, cold side & $\Delta p[\mathrm{bar}]$ & 1.5 & Datasheet \\
\hline Oil-water heat exchanger, hot side & $\Delta p[\mathrm{bar}]$ & 1.5 & Datasheet \\
\hline Oil-water heat exchanger, cold side & $\Delta p[\mathrm{bar}]$ & 1.5 & Datasheet \\
\hline Oil heater, hot side & $\Delta p[\mathrm{bar}]$ & 1.0 & Datasheet \\
\hline Oil heater, cold side & $\Delta p[\mathrm{bar}]$ & 1.5 & Datasheet \\
\hline Water pump & $\eta[\%]$ & 75 & Assumed \\
\hline 1st oil pump & $\eta[\%]$ & 76 & Pump performance curves \\
\hline 2nd oil pump & $\eta[\%]$ & 74 & Pump performance curves \\
\hline \multicolumn{4}{|l|}{ Gas treatment } \\
\hline Split flow ratio, gas for recirculation, 1st stage & {$[-]$} & 0 & Assumed, operators \\
\hline \multicolumn{4}{|l|}{ Hot water system } \\
\hline Heating medium, water mass fraction & $x_{\text {water }}[-]$ & 1.00 & Documentation of hot water system \\
\hline Delivery pressure & $p[\mathrm{bar}]$ & 25.9 & Documentation of hot water system \\
\hline Delivery temperature & $T\left[{ }^{\circ} \mathrm{C}\right]$ & 170 & Documentation of hot water system \\
\hline Return temperature & $T\left[{ }^{\circ} \mathrm{C}\right]$ & 120 & Documentation of hot water system \\
\hline \multicolumn{4}{|l|}{ Cooling system } \\
\hline Cooling medium, water mass fraction & $x_{\text {water }}[-]$ & 1.00 & Assumed \\
\hline Delivery pressure & $p[\mathrm{bar}]$ & 11.4 & Documentation of seawater system \\
\hline Delivery temperature & $T\left[{ }^{\circ} \mathrm{C}\right]$ & 10 & Documentation of seawater system \\
\hline Return temperature & $T\left[{ }^{\circ} \mathrm{C}\right]$ & 45 & Documentation of seawater system \\
\hline
\end{tabular}


Table A.22: Measured values for temperature, $T$, pressure, $p$, and flow, $F$, compared with simulated values for Platform C.

\begin{tabular}{|c|c|c|c|}
\hline Process stream description & Variable & Measured value & Simulated value \\
\hline \multicolumn{4}{|c|}{ High pressure production manifold } \\
\hline From well 2 , valve, out & $T\left[{ }^{\circ} \mathrm{C}\right]$ & 61.5 & 61.6 \\
\hline From well 6 , valve, out & $T\left[{ }^{\circ} \mathrm{C}\right]$ & 62.7 & 62.9 \\
\hline From well 8 , valve, out & $T\left[{ }^{\circ} \mathrm{C}\right]$ & 53.9 & 53.2 \\
\hline From well 9, valve, out & $T\left[{ }^{\circ} \mathrm{C}\right]$ & 58.6 & 56.5 \\
\hline From well 10, valve, out & $T\left[{ }^{\circ} \mathrm{C}\right]$ & 58.5 & 58.2 \\
\hline From well 15 , valve, out & $T\left[{ }^{\circ} \mathrm{C}\right]$ & 70.7 & 70.9 \\
\hline From well 16 , valve, out & $T\left[{ }^{\circ} \mathrm{C}\right]$ & 64.7 & 64.7 \\
\hline From well 17, valve, out & $T\left[{ }^{\circ} \mathrm{C}\right]$ & 43.4 & 43.6 \\
\hline From well 18 , valve, out & $T\left[{ }^{\circ} \mathrm{C}\right]$ & 51.6 & 50.7 \\
\hline From well 19, valve, out & $T\left[{ }^{\circ} \mathrm{C}\right]$ & 59.9 & 59.8 \\
\hline From well 21, valve, out & $T\left[{ }^{\circ} \mathrm{C}\right]$ & 47.0 & 45.9 \\
\hline From well 25 , valve, out & $T\left[{ }^{\circ} \mathrm{C}\right]$ & 56.7 & 57.1 \\
\hline From well 26 , valve, out & $T\left[{ }^{\circ} \mathrm{C}\right]$ & 57.8 & 57.1 \\
\hline From well 27 , valve, out & $T\left[{ }^{\circ} \mathrm{C}\right]$ & 55.5 & 54.7 \\
\hline From well 28 , valve, out & $T\left[{ }^{\circ} \mathrm{C}\right]$ & 57.1 & 56.8 \\
\hline From well 30 , valve, out & $T\left[{ }^{\circ} \mathrm{C}\right]$ & 61.5 & 61.6 \\
\hline From well 35 , valve, out & $T\left[{ }^{\circ} \mathrm{C}\right]$ & 63.7 & 63.6 \\
\hline From well 40 , valve, out & $T\left[{ }^{\circ} \mathrm{C}\right]$ & 62.1 & 62.1 \\
\hline \multicolumn{4}{|c|}{ Low pressure production manifold } \\
\hline From well 3 , valve, out & $T\left[{ }^{\circ} \mathrm{C}\right]$ & 70.5 & 71.0 \\
\hline From well 12 , valve, out & $T\left[{ }^{\circ} \mathrm{C}\right]$ & 53.0 & 51.3 \\
\hline From well 13 , valve, out & $T\left[{ }^{\circ} \mathrm{C}\right]$ & 70.6 & 70.9 \\
\hline From well 22 , valve, out & $T\left[{ }^{\circ} \mathrm{C}\right]$ & 52.0 & 55.7 \\
\hline From well 34 , valve, out & $T\left[{ }^{\circ} \mathrm{C}\right]$ & 54.9 & 57.4 \\
\hline $\begin{array}{l}\text { From well } 39 \text {, valve, out } \\
\text { Test manifold }\end{array}$ & $T\left[{ }^{\circ} \mathrm{C}\right]$ & 70.8 & 71.9 \\
\hline $\begin{array}{l}\text { From well } 1 \text {, valve, out } \\
\text { Separation and oil export }\end{array}$ & $T\left[{ }^{\circ} \mathrm{C}\right]$ & 64.9 & 65.0 \\
\hline Water pump, in & $p$ [bar] & 4.20 & 2.75 \\
\hline 1st oil pump, in & $p[\mathrm{bar}]$ & 3.96 & 2.75 \\
\hline 1st separator, in & $T\left[{ }^{\circ} \mathrm{C}\right]$ & 65.1 & 65.5 \\
\hline 2nd separator, in & $T\left[{ }^{\circ} \mathrm{C}\right]$ & 96.6 & 97.2 \\
\hline 2nd oil pump, out & $F\left[\mathrm{Sm}^{3} / \mathrm{h}\right]$ & 1000 & 1100 \\
\hline Gas treatment & & & \\
\hline 1st compressor, in & $F\left[\mathrm{Sm}^{3} / \mathrm{h}\right]$ & 240,000 & 230,000 \\
\hline $\begin{array}{l}\text { 2nd compressor, in } \\
\text { Fuel gas system }\end{array}$ & $F\left[\mathrm{Sm}^{3} / \mathrm{h}\right]$ & 260,000 & 230,000 \\
\hline Heater, in & $T\left[{ }^{\circ} \mathrm{C}\right]$ & 23.1 & 24.2 \\
\hline
\end{tabular}

